\title{
EVALUATING MICRO-SURVEY ESTIMATES OF WEALTH AND SAVING
}

Barry P. Bosworth and Rosanna Smart*

CRR WP 2009-4

Released: January 2009

Draft Submitted: January 2009

\author{
Center for Retirement Research at Boston College \\ Hovey House \\ 140 Commonwealth Avenue \\ Chestnut Hill, MA 02467 \\ Tel: 617-552-1762 Fax: 617-552-0191
}

* Barry P. Bosworth is a senior fellow at The Brookings Institution. Rosanna Smart is a senior research assistant at The Brookings Institution. The research reported herein was performed pursuant to a grant from the U.S. Social Security Administration (SSA) funded as part of the Retirement Research Consortium. The opinions and conclusions expressed are solely those of the authors and should not be construed as representing the opinions or policy of SSA, any agency of the Federal Government, The Brookings Institution, or Boston College.

(C) 2009, by Barry P. Bosworth and Rosanna Smart. All rights reserved. Short sections of text, not to exceed two paragraphs, may be quoted without explicit permission provided that full credit, including $(\subset)$ notice, is given to the source. 


\title{
About the Center for Retirement Research
}

The Center for Retirement Research at Boston College, part of a consortium that includes parallel centers at the University of Michigan and the National Bureau of Economic Research, was established in 1998 through a grant from the Social Security

Administration. The Center's mission is to produce first-class research and forge a strong link between the academic community and decision makers in the public and private sectors around an issue of critical importance to the nation's future. To achieve this mission, the Center sponsors a wide variety of research projects, transmits new findings to a broad audience, trains new scholars, and broadens access to valuable data sources.

\author{
Center for Retirement Research at Boston College \\ Hovey House \\ 140 Commonwealth Avenue \\ Chestnut Hill, MA 02467 \\ phone: 617-552-1762 fax: 617-552-0191 \\ e-mail: crr@bc.edu \\ www.bc.edu/crr
}

\author{
Affiliated Institutions: \\ The Brookings Institution \\ Massachusetts Institute of Technology \\ Syracuse University \\ Urban Institute
}




\begin{abstract}
This paper presents an overview of changes in household wealth accumulation and saving using wealth data from three micro-level surveys: Survey of Consumer Finances (SCF), Panel Study of Income Dynamics (PSID), and Health and Retirement Study (HRS). We provide comparisons to the macroeconomic estimates of wealth accumulation and saving, explore problems in constructing household-level valuations of wealth, and assess the value of using household-level datasets to examine wealth accumulation and saving behavior in the United States.

Our first analysis compares the macroeconomic estimates of wealth from the Flow of Funds to comparable measures from the SCF, PSID and HRS. The Flow of Funds and SCF valuations of net worth correspond closely up to 1998. Yet, after1998, the SCF reports a much more rapid acceleration of wealth, concentrated in equity-type assets. The estimates of wealth in the PSID and HRS are very similar to the SCF for the bottom 95 percent of the wealth distribution, diverging only for the top five percent of households.
\end{abstract}

Second, we evaluate the extent of bias in the wealth estimates that may have developed in the longitudinal surveys due to attrition. We conclude that both surveys remain very representative of the underlying population as judged by a comparison with the lower 95 percent of households in the SCF. We also use the longitudinal data to estimate the relationship between wealth and mortality, and adjustment factors for differential mortality that can be used to adjust the age-wealth profile obtained from cross-sectional surveys, such as the SCF. The result is greater evidence of wealth decumulation at older ages.

Finally, we use the panel nature of the PSID and HRS to construct household-level measures of wealth accumulation and partition those changes between the contribution of new saving and valuation changes. The overall changes in wealth match the macroeconomic data closely, showing a secular rise in wealth-income ratios. Although the measures of saving do demonstrate consistent differences in saving among major socio-economic groups, they do not reflect the general decline in saving rates that is apparent in the aggregate data for the past two decades. 


\section{Introduction}

The macroeconomic data of the national accounts document a severe and sustained decline in the household saving rate, ongoing now for over a quarter of a century. Yet, despite a voluminous quantity of economic research, a consensus on the causes of the decline has not emerged. Prior studies have drawn attention to some of the characteristics of the change in saving: the extraordinary growth in capital gains, the influence of alternative concepts of saving, and the growing role of pension funds and other forms of contractual retirement saving. Agreement on the fundamental causes, however, remains elusive. The discussion has been complicated by the fact that another closely-related measure, the household wealth-income ratio, has actually risen substantially over much of the period when saving rates have been depressed. This dichotomy gives rise to a natural question: if Americans save so little, why are they so rich? It has led some researchers to dismiss the household saving measure as the product of a faulty conceptual framework.

The macroeconomic analysis encounters a fundamental problem in that the falloff in the saving rate is largely a single non-recurring event, albeit one that extends over several years. In the absence of greater variation and repeated episodes of similar changes within the United States or other countries, the data are simply not sufficient to

distinguish among the various competing hypotheses. Frustrations with the limitations to research using aggregate data have led to a growing focus on household-level surveys that provide increasing detail on wealth, its composition, and some of its primary determinants.

This paper examines trends in saving and wealth accumulation from a microeconomic perspective as reported in three household-level surveys and benchmarks those results to comparable aggregate concepts. Using the Survey of Consumer Finances, the Panel Study of Income Dynamics, and the Health and Retirement Study, we can identify changes in saving and wealth accumulation among differing socio-economic groups; thus, a major goal is to identify those whose saving has changed. Rather than 
reflecting the behavior of the 'typical' consumer, the decline in overall saving may instead be attributable to large changes in the actions of a limited number of groups or a specific age cohort. At the same time, since they offer a rich source of variation in the basic determinants of saving and its composition, the surveys may provide some direct evidence on the causes of the decline.

The micro surveys, however, introduce their own problems of potentially large measurement error and sample selection bias. As a result, much of this report is devoted to an evaluation of the quality of the three surveys and the extent to which the reported measures of wealth and saving are consistent with the macroeconomic data.

\section{The Surveys}

The Survey of Consumer Finances (SCF) has been conducted on a triennial basis since 1983, but the 1986 survey was limited to a phone reinterview of participants in the 1983 survey. We have focused on the seven longer interviews stretching over two decades from 1983 to 2004. The major innovation in the design of the SCF has been the use of a dual-frame sample design (Kennickell, 2000). The first component consists of a national area-probability sample designed to be representative of the total population. However, given the highly skewed distribution of wealth holdings and higher refusal rates for high income families, the sample would have to be very large in order to obtain accurate estimates of wealth holdings at the top of the distribution. Thus, it is supplemented by a special list sample compiled from tax return data. ${ }^{1}$ Each wave of the SCF is an independent cross-section estimate of net worth in that it is based on a newly drawn sample. Except for a small number of 3,143 cases in 1989, the sample size has ranged between 4 and $4 \frac{1}{2}$ thousand observations. The extent of oversampling of households in top portions of the distribution is also very large: in the 2004 survey, for example, households in the top 5 percent of the wealth distribution accounted for 26 percent of the sample observations. The major disadvantage of the SCF is that, as a

\footnotetext{
${ }^{1}$ A second important feature of the data set is the incorporation of a multiple imputation procedure for missing data that is designed to maintain the mean and variance of the original responses. Each observation is replicated five times in 1989 and later years with five different values for the imputed variables. A different imputation procedure with a single observation was used for the 1983 survey.
} 
series of cross-sectional estimates wealth, it can provide no information on the evolution of wealth holdings at the household level.

The Panel Study of Income Dynamics (PSID) is an alternative longitudinal survey that has followed a sample of families and their descendents since 1968. It is designed to collect data on a very wide range of economic and sociological behavior. Except for immigration, the PSID mimics the dynamics of the aggregate population change as it follows members who leave to form new families, and it incorporates the effects of death and divorce. The supplemental wealth module was introduced in 1984 and was conducted on a periodic basis prior to 1999 (the 1984, 1989, and 1994 waves). Since 1997 the basic PSID survey has been conducted biennially, and starting with 1999 the wealth and active saving questions have been included in each wave (1999, 2001, 2003, and 2005). At present, seven waves of the survey have wealth information, and the number of observations varies between seven and eight thousand households.

The PSID questions on wealth holdings are far more limited than those of the SCF with only eight asset components: (1) home equity, (2) other real estate, (3) private business/farm, (4) vehicles, (5) transaction accounts, (6) corporate equities, (7) annuities/IRAs, and (8) other savings. ${ }^{2}$ All of these assets are defined net of any associated debt. In addition, information is collected on a ninth category of noncollateralized debt. Home equity can be computed on an annual basis from information on home value and mortgage debt prior to 1999 and biennially in later years. The other components, however, are limited to the specific years of the wealth supplement. The questions have remained the same over time except for the separate identification of annuities and IRAs beginning in $1999 .^{3}$ Previously, the questions on transaction accounts

\footnotetext{
${ }^{2}$ More complete definitions of the asset categories are provided in appendix B, based on the wealth questions from the 2005 wave of the survey. We exclude vehicle wealth and purchases from all of our analysis because the valuation of such assets is not consistent across the three surveys.

${ }^{3}$ The shift to a specific question about IRAs creates some discontinuities because we do not know the asset composition of the IRA accounts. Furthermore, the dollar value of the unfolding brackets used for respondents who did not give a precise answer to the wealth questions changed somewhat between 1984 and 1989, but remained the same thereafter. The unfolding bracket methodology was introduced for housing in the 2005 wave.
} 
and corporate equities were inclusive of funds in IRAs, but there was no specific mention of annuities.

In addition, beginning with the 1989 wealth supplement, questions have been asked about purchases and sales of other real estate, private business, and corporate equities since the prior wealth survey. These are the three wealth components, in addition to main residence, that are subject to valuation changes. Finally, the PSID wealth modules have not been fully checked for entry errors. We undertook a preliminary effort to correct for some the more extreme and obvious entry errors as documented in Appendix A. The corrections affected about 100 cases in each wave of the survey.

The Health and Retirement Study (HRS) is a longitudinal sample like the PSID, but it is limited to respondents who are over age 50 and their spouses. The original 193141 birth cohort was introduced in 1992 and a matching questionnaire for the AHEAD cohort (born prior to 1923) was adopted in 1993. The cohort of persons born in 1923-30 was added in 1998, and younger cohorts are scheduled to be added on a regular basis. The re-interviews occur on a biennial cycle; and the wealth and active saving questions follow the framework of the PSID, but with more detail about some transactions. While the survey is not representative of the full population, it is larger than either the PSID or the SCF, varying between 12 and 17 thousand observations in the recent waves. ${ }^{4}$ Again, there are seven available waves beginning in 1992. As with the PSID, we made a number of changes, affecting about 100 cases in each wave, for what appeared to be entry errors in the reported wealth values.

\section{Major Conclusions}

Our findings can be grouped, however, into three main areas, as follows: First, for the measures of wealth, the micro surveys capture the main elements of the macroeconomic data as reported in the flow of funds accounts in terms of growth over time and changes in the composition of household wealth. For example, all three surveys

\footnotetext{
${ }^{4}$ There are some problems with aligning household units between the HRS and other two surveys. The SCF and PSID use comparable definitions of family units, but the HRS collects information on individuals from the appropriate age cohort and their spouses. Thus, elderly persons living with adult children are included as separate household units in the HRS but not the PSID or SCF. We aligned couple households in the three surveys by the age of the head, whom we define as the male or oldest partner.
} 
report a sharp rise in the household wealth-income ratio beginning in the mid-1990s. Only the Survey of Consumer Finances, however, with its special focus on families with high capital income, is able to capture fully the wealth holdings at the very top of the wealth distribution. Significantly, the SCF does depart from the macroeconomic data in reporting a substantially larger rise in wealth over the period of 1999-2004.

The major advantage of the two longitudinal surveys lies with their ability to provide information on the evolution of household wealth holdings over time. Despite their reliance on a very small number of wealth questions, the PSID and the HRS match very closely with the SCF as long as the comparison is limited to households below the top five percent of the wealth distribution. However, both longitudinal surveys suggest a smaller surge in wealth accumulation after 1998. In that respect, they are closer to the pattern of the F/Fs than the SCF. The discrepancy between the SCF and the two longitudinal surveys is concentrated in the category of equity-type wealth (real estate, businesses, and equity-holdings). They yield similar estimates of home equity and fixedprice assets (deposits and bonds). Consistent with the finding that the two longitudinal surveys lack coverage of families at the top of the wealth distribution, the discrepancies in the estimates of wealth are an increasing function of both age and education.

Second, there is a concern that longitudinal surveys, such as the PSID and the HRS, can yield non-representative estimates of wealth across socio-economic groups due to sample attrition. The characteristic of those who leave the sample may differ in systematic ways from those who remain in the sample. We are able to tabulate wealth separately for those who participated in all seven waves of the surveys, those who left due to death, and those who left for other reasons. In the case of the HRS there is very little difference in the wealth of those who stay and those who leave for reasons other than death. However, persons who died between 1992 and 2006 had average wealth holdings less than 60 percent of those who remained in the survey. We use the data from the HRS to derive a mortality correction factor that can be applied to age profiles from cross-sectional surveys such as the SCF. The result is an age-wealth profile that yields much stronger evidence of declines in wealth at older ages. The PSID has a higher rate of attrition that the HRS, and there is more evidence that those who exit from the survey have lower wealth than those who stay. The evidence of a mortality bias in the wealth 
data is less pronounced, but that appears to be due to the wider age range of households that are included in the PSID, and less complete data on the mortality of persons who exited from the survey.

Third, we constructed measures of the change in net worth and divided that change between two components of active and passive (capital gains) saving. For the SCF, where we lack matching measures of wealth at the individual level between surveys, the computation of the change in wealth and the division between saving and valuation changes can only be done at the most aggregative level. We judged that effort to be ineffective.

For the two longitudinal surveys we have match estimates of households' wealth across the various waves of the survey, and for those wealth components that are subject to valuation changes, the surveys included a set of questions aimed at measuring net asset purchases. Thus we can also divide the change in wealth between active and passive saving. The measures of wealth accumulation do accord with the macroeconomic data in indicating a secular rise in wealth-income ratios. While the saving component does not capture the phenomenon of a general decline in household saving over the past two decades, the saving measures show consistent differences in saving rates across various socio-economic groups. In regression analysis, saving is systematically related to income, age and initial wealth holding, but the proportion of the variance over time that can be explained by such measures is very low.

The primary problems with the estimates of saving and wealth change from the surveys center around serious problems with measurement error. While measurement errors in the cross-section estimates of wealth can be assumed to be random, they take on a much larger role in the estimate of the change in asset values. The indirect estimation of active and passive saving as the difference between two independently obtained measures of wealth yields estimates of saving with very high noise-to-signal ratios. The estimates of saving could be greatly improved by developing methods to reduce the variability of the responses across waves of the survey. 


\section{Comparison of Wealth Trends}

The evaluation of the wealth data proceeds by first analyzing the extent to which the wealth estimates in the SCF are comparable to the macroeconomic level estimates of the Flow of Funds (F/Fs) both in terms of the changes over time and for specific categories of asset and liabilities. The SCF is used in turn as the benchmark for evaluating the micro-level wealth measures that we obtain from the PSID and the HRS.

$\boldsymbol{S C F} v \boldsymbol{v} . \boldsymbol{F} / \boldsymbol{F}$. Our comparison of the SCF and the F/Fs is an extension of earlier work (Bosworth and Bell, 2005) to cover the latest waves of the surveys. The F/Fs reports aggregate values for major categories of assets and liabilities and for major sectors of the economy. The estimates for the household sector are, however, largely a residual obtained by subtracting the holdings of other sectors from national totals. We use averages of the beginning and end of year F/F values. The procedures for grouping the survey responses into categories that are comparable to those of the F/Fs draws heavily on the work of Antoniewicz (2000). ${ }^{5}$ Our results are similar to those of Antoniewicz for the early years and we have extended her methodology to cover the SCF surveys of 1983, 2001 and 2004. A summary comparison is provided in figure 1 and a more detailed match by asset category is provide in Appendix table A1. There are some components of household wealth in the F/Fs that are not captured in the SCF, such as employer-provided defined-benefit plans; and there are other elements of the SCF that cannot be matched to comparable F/F concepts. The figure displays the total from the two sources for the matched components and a total that includes all the components for a definition of net worth excluding only pensions and consumer durables

In the 1983 through 1999 surveys, the matching portions are very similar, and the SCF estimates of total net worth range between 88 and 95 percent of the corresponding F/Fs estimates. The close correspondence between the SCF and the F/Fs in the earlier years is an encouraging assessment of both data series. However, the differences are much more pronounced in 2001 and 2004, and the SCF estimates for the matching components exceed those of the $\mathrm{F} / \mathrm{F}$ by $\$ 5$ and $\$ 9$ trillion respectively in those two years

\footnotetext{
${ }^{5}$ Some early comparisons to the F/Fs were provided by Curtin and others (1989), and more recently by Sabelhaus and Pence (1999).
} 
(representing 18 and 30 percent of net worth in the F/Fs, respectively). The discrepancies are concentrated on the asset side of the balance sheet in the categories of closely-held corporate equity, noncorporate businesses, and owner-occupied real estate. These are areas for which the F/Fs are lacking high-quality source data; yet the values reported in the SCF are largely based on respondent valuations, rather than a market benchmark. Thus, it is not easy to conclude which is the more accurate measure.

Adjusted for inflation, the SCF estimate of wealth grew at a 4.2 percent annual rate in 1983-98, only slightly below the 5 percent rate reported in for the F/Fs. Between 1998 and 2004, however, the SCF estimate accelerated to 7.7 percent per year versus a 3 percent rate in the F/Fs. The result is a much larger rise in the wealth-income ratio in recent years than suggested by the macroeconomic data. The F/Fs data indicate that the wealth-income ratio peaked in 1999 and declined significantly in subsequent years. The SCF, on the other hand, suggests that the gains in wealth continued to outpace the growth of incomes through 2004.

SCF vs. PSID. The PSID collects no significant information on the value of employer-provided pensions. Thus, in the comparison of the micro-surveys our definition of wealth excludes all funds held within pension funds as well as the value of vehicles. The comparison of the PSID and HRS wealth data is an update of a prior study by Juster, Smith, and Stafford (1999), who examined the results from the first three wealth supplements of the PSID (1984, 1989, and 1994). ${ }^{6}$ The two surveys use virtually identical definitions of the household unit, so we focus on the comparison of mean wealth per family. ${ }^{7}$

The basic results are summarized in figure 2 for the years of 1983 to 2005 . While each survey has generated seven waves over that period, there is a precise overlap only in 1989 and 2001. The top two lines report average wealth holdings in 2000 dollars for the full population of all families. Congruous with the findings of Juster and others, the PSID consistently reports a much lower level of wealth than the SCF. In 2001, the PSID

\footnotetext{
${ }^{6}$ Comparisons were also reported in Hurst and others (1998).

${ }^{7}$ The distributions of families in the two surveys are very similar for other socio-economic characteristics. The PSID is a consistently younger population when classified by the age of the head, but by a small amount; and the distribution by the educational attainment of the head is virtually identical.
} 
measure of average wealth was only 63 percent of the comparable value from the SCF. There is significant variation over time, with the gap between the two estimates narrowing in the 1990s and widening in 2001 and later years, a pattern that follows that reported for the earlier comparison of the SCF and F/Fs.

The results are consistent with the argument that the SCF does a much better job of estimating the full range of the wealth distribution by the use of the special sampling frame to capture high-wealth households. Interesting support for that hypothesis is provided by the lower two lines in figure 2, which represent the mean wealth holdings of families up to the $95^{\text {th }}$ percentile of the wealth distribution as defined by the dollar breakpoints in the SCF. The two surveys report nearly identical measures of wealth for those families, and the difference shows no consistent pattern of change over time. This finding is surprising given the PSID has very few questions about wealth holdings relative to the highly detailed questions of the SCF. Thus, the difference in the structure of the sampling frames is a much more significant issue than the structure of the questionnaire. It is also notable that the surge in wealth values reported in the 2001 and 2004 waves of the SCF is less evident in the PSID.

The similarity of the results from the two surveys in the lower portions of the wealth distribution is even more apparent in table 1 . The table reports mean wealth holdings by deciles for 1989 and 2001, years in which the two surveys coincided. Again, the decile breakpoints are defined by the dollar magnitudes of the SCF. The distributions appear remarkable similar up to the $95^{\text {th }}$ percentile, but the 1989 mean wealth of the top 5 percent of families is estimated at \$2.6 million in the SCF compared to \$2.0 million in the PSID. By 2001, the difference had grown substantially as the SCF reported an average wealth of $\$ 4.3$ million compared to $\$ 3.0$ million in the PSID. More importantly, the PSID reports an incidence of families in the category that is only about half that of the SCF. It is also striking that the two surveys report identical rates of wealth accumulation over the full period of 1983/84 to2004/05, 3.3 percent per year. ${ }^{8}$ However, wealth in the

\footnotetext{
${ }^{8}$ The reported growth rates differ from those reported in the comparison of the SCF and the F/F because of the exclusion of all pension accounts and the reporting of the data on a per household basis.
} 
SCF grew at a lower rate prior to 1995, and displays a more substantial acceleration in the latest surveys.

Figure 3 shows how mean wealth holdings have evolved over time for households of different ages and educational attainment. In the SCF (panel a), the cross-sectional age-wealth profiles are shifting up over time, reflecting the increased economic resources of successive cohorts, but the age-profiles are also becoming much more steeply sloped. The largest percentage wealth gains between 1983 and 2004 are reported for those households with a head over age 50 . This result is clearly driven by the dominant role of capital gains in 1998 and later years. Younger households show very modest increases in wealth because they have smaller portions of their wealth subject to capital gains. The PSID data presented in panel (b) show the same pattern of an increasing slope to the agewealth profile and a pronounced rise in 1998 and later years. However, the PSID profiles appear severely truncated at older ages because the discrepancy between the SCF and the PSID wealth estimates is an increasing function of age. For example, the SCF estimate of wealth in 2004 for the 25-39 age group exceeds that of the PSID by 23 percent, but the difference is 73 percent for the 50-59 age category and 67 percent for ages 60-69.

Wealth also increases with educational attainment (panel c), and the gradient in the SCF has increased substantially over time for professionals and others with graduate educations. ${ }^{9}$ For example, in 2004 the mean wealth of college graduates was 4 times higher than the wealth of those who had a high school degree. For those with a graduate education, wealth was 6.5 times the wealth of high school graduates in 2004, compared with a multiple of only 3 in 1983. Again however, the educational profiles are notably flatter in the PSID: as with age, the discrepancy between the SCF and the PSID estimates of wealth rises sharply with educational attainment. The wealth of those with a postgraduate education in the 2004 SCF exceeded the average of the 2003 and 2005 waves of the PSID by 93 percent, and the gap was 52 percent for college graduates.

It is also notable that the differences between the SCF and the PSID are much smaller for income than for wealth (table A2). On average over the 1983-2005 years, the income estimates in the SCF have been about 10 percent higher than those of the PSID, compared with a 50 percent difference for wealth. Thus, the SCF differs primarily by

\footnotetext{
${ }^{9}$ In the figure, the education-wealth profiles from the 2001 and 2004 surveys are nearly identical.
} 
including households that have higher wealth-income ratios instead of simply being richer. Perhaps, we should not be surprised since high levels of capital income are the primarily indicator used to select households for the IRS-based list sample. As with wealth, the discrepancies in income increase with age and educational attainment.

Finally, we have grouped wealth into three categories of: (1) main home equity, (2) fixed-price assets, and (3) equity-type assets subject to capital gains/losses. This division corresponds to questions directed toward measuring active and passive saving in the PSID. As shown in figure 4, the discrepancies between the SCF and the PSID in recent years are concentrated in the category of wealth subject to capital gains/losses. It includes business assets, real estate other than main home and corporate equities; and it represents a large portion of the holdings of households at the top of the wealth distribution. The SCF also reports a somewhat more rapid rate of increase in respondents' valuation of their home equity.

We conclude that the PSID does a surprisingly good job of tracking the wealth of the 'typical' or median family, but it does not fully capture the behavior of high-wealth families. The discrepancies are concentrated among older households, those with high levels of education, and those who have large portion of their wealth invested in equitytype assets. While this is a significant shortcoming, the PSID is the only survey that allows us to follow the saving and wealth accumulation of a broad representation of individual families over time. ${ }^{10}$

SCF vs. HRS. The HRS is of limited value for measuring aggregate trends in wealth accumulation because it is limited to aged households, but it is a large survey covering those age cohorts that account for a dominant portion of total wealth. In the 2004 SCF, for example, 70 percent of total wealth was held in households whose head was born in the years before 1954 (the age cohorts included in that year's wave of the HRS). Figure 5 provides a comparison of the wealth estimates from the HRS with those for comparable age categories of the SCF and PSID. The age cohorts that are included in the survey have expanded with successive waves of the HRS. Therefore, we adjusted the

\footnotetext{
${ }^{10}$ The Survey of Program Participation reports estimates of wealth, but it appears to miss an even larger portion than the PSID. See Czajka and others (2003). The panel dimension of the data is also very limited.
} 
age categories of the SCF and PSID over time to match those of the comparable wave of the HRS. The definition of a household in the HRS is adjusted to match as closely as possible the concepts of the SCF.

The gap between the SCF and the HRS estimates of average wealth holdings is very large, as was previously the case for the PSID. The mean wealth from the 2004 wave of the HRS is only 74 percent of the value from the corresponding age group of the SCF, and the average of the estimates for 2000 and 2002 is about 60 percent of the 2001 SCF. As shown in the figure, the HRS wealth values are much more similar to those of the PSID. In fact, the HRS appears to have the same problem as the PSID of not including a sufficient number of households at the top of the wealth distribution. For example, the estimates of average household wealth holdings of aged households are quite similar across all three surveys if the comparison is limited to households up to the $95^{\text {th }}$ percentile of the SCF distribution (figure 5). ${ }^{11}$ However, average wealth below the $95^{\text {th }}$ percentile distribution grows considerably more slowly in the HRS over the full 1992-2004 period than the corresponding measures from the either the SCF or the PSID. The HRS reports an average value of wealth for households below the $95^{\text {th }}$ percentile that is 40 percent above the estimate of the corresponding cohort in the SCF in 1992, but 10 percent below in 2004.

The results for individual birth cohorts of the HRS are shown in figure 6. The comparison of mean wealth across the three surveys for the original 1931-41 birth cohort are very similar to those shown previously for the total survey. However, the HRS estimates for the older cohort, those born before 1924, are significantly higher than comparable data from the PSID, but still far below the SCF. In contrast, the HRS estimates for the 1924-30 and 1942-47 cohorts are actually less than those of the PSID; but, the sample sizes in these narrow age categories are quite small in the SCF and PSID and the estimates may not be very reliable.

We also examined differences in wealth holdings by levels of educational attainment. Average wealth holdings of the 1931-41 birth cohort rise sharply with

\footnotetext{
${ }^{11}$ Like the PSID, the HRS has very little representation of households above the $95^{\text {th }}$ percentile cutoff of the wealth distribution as recorded by the SCF. Whereas 26 percent of the households in the SCF sample were in that wealth range, only 2 percent of the PSID sample and 3 percent of the HRS sample have wealth above that level.
} 
educational attainment (figure 7). And, as with the PSID and SCF data for households of all ages, the gradient increases over time. However, comparisons between the HRS and either the SCF or the PSID are limited by the small sample size for the latter two surveys when they are restricted to a specific age cohort and level of educational attainment. Therefore, we averaged the results of the 2001 and 2004 SCFs for a comparison with the 2002 HRS. In the SCF, mean wealth of a family whose head was in the 1931-41 birth cohort and had a college degree or graduate education, was $\$ 1.5$ million compared to $\$ 772$ thousand in the HRS. A similar average estimate from the 2001 and 2003 PSID yields a cohort mean of $\$ 852$ thousand. Again, the HRS and PSID yield very similar wealth estimates, but fall short of the SCF.

Finally, it is notable that the discrepancies between the wealth estimates from the SCF and the HRS are not matched by the differences in the estimates of income. The ratios of wealth and income in each year of the SCF survey to the comparable estimates from the HRS for the 1931-41 birth cohorts for each level of educational attainment are shown in table $2 .{ }^{12}$ The average value for 1992-2004 is shown in the last column. On average, the wealth estimates of the SCF exceeded those of the HRS by 51 percent, but the excess was as low as 40 percent in 2004 and as high as 77 percent in 2001. It is also evident that the differential rises sharply with education, although the individual estimates from the SCF are volatile due to the small sample size. In contrast, the income estimates of the SCF averaged only 14 percent higher than those of the HRS, and the increase by level of education is much more modest than for wealth.

In summary, despite its much larger sample size and more detailed questions on wealth, the HRS produces estimates of average wealth balances for older households that are remarkably similar to those of PSID, but far below those found in the SCF. It appears to suffer from the same shortcoming as the PSID of an inadequate representation of households at the top of the wealth distribution.

\footnotetext{
${ }^{12}$ The surveys overlapped in 1992, 1998, and 2004. For 1995 and 2001, the denominator is the average of the two surrounding HRS waves.
} 


\section{The Role of Attrition and Mortality}

It is evident that the SCF provides the most complete perspective on the distribution of wealth; yet, because it is based on periodic cross-section snapshots, it is limited as a tool for exploring the pattern and sources of wealth accumulation. For example, Shorrocks (1975) pointed out that the age-wealth profile obtained from a single cross-section survey is distorted in two respects. First, there is a productivity bias that flattens the age-wealth profile because younger cohorts have higher earnings and ceteris paribus higher wealth than older cohorts at the same age. On the other hand, there is a mortality bias that tilts the age-wealth profile up because poorer households die at younger ages. Thus, age-wealth profiles from cross-sectional surveys may present overly optimistic or pessimistic perspectives on the outlook for the future well-being of the elderly.

It is possible to control for the productivity bias by linking common birth cohorts across successive waves of the cross-section survey to construct a synthetic panel (Deaton, 1985). However, the linkage does introduce a certain amount of volatility because of changing family structures. Nor can the method adjust for mortality bias.

This mortality bias is a great concern for longitudinal surveys, such as the PSID and HRS, which can be biased due to various forms of attrition from the sample. The attributes of those who leave may systematically differ from the characteristics of those who are retained in the sample. In this section, we report on the results of our analysis of how attrition from the two surveys affects reported patterns of wealth accumulation. At the same time, the analysis of those who leave the longitudinal sample due to their death provides a direct estimate of the mortality bias in the cross-section surveys.

There have been several major studies of attrition in both the PSID and HRS. Fitzgerald and others (1998) and Lillard and Panis (1998) reported on the effects of attrition in the PSID. They both concluded that the survey remains highly representative of the overall population despite a significant degree of attrition since its inception. In effect, the attrition appears to have been quite random and they find little evidence of bias in the various characteristics that they examined. Neither study focused on the effects of attrition on wealth. 
More recently, Kapteyn and others (2006) examined the experience with attrition in the HRS through the 2002 wave. Focusing on the 1931-41 birth cohort, they found a bit more evidence of selection bias, largely with respect to observables such as race and ethnicity, that could be corrected through reweighting of the sample. The authors do find substantial differences in the wealth holdings of the temporary and permanent attritors. Among the permanent attritors, those who died had particularly low wealth and income in the base year of 1992.

Attanasio and Hoynes (2000) provide estimates of the magnitude of the mortality bias using data from the Survey of Income and Program Participation and the Consumer Expenditure Survey. They find evidence of a very large mortality effect, but one that is concentrated in the lower portions of the wealth distribution. Their study provides a clear methodology for estimating the extent of the bias, but it suffers from the reliance on two surveys that are known to underestimate household wealth holdings by large amounts. ${ }^{13}$ We extend their analysis by using both the PSID and the HRS as sources of information on the relationship between mortality and wealth.

Attrition and Mortality in the HRS. Some summary results on attrition from the HRS are shown in table 3, which reports the proportion of each two-year birth cohort (column) and 1992 wealth quintile (row) that left the survey at some time between 1992 and 2004. For example, in the group of individuals born in 1931-32 and who ranked in the lowest quintile of the wealth distribution, 32 percent died over the period and 9 percent left for other reasons. Information on deaths is taken from the 2006 HRS tracker file, which has been significantly updated with respect to information on prior deaths. As expected, death rates are significantly lower for younger cohorts, but there is no particular pattern to attrition for other reasons. The most notable feature is the large decline in mortality in the upper portions of the wealth distribution. Averaging across the age groups, the mortality rate falls from 5.5 percent for the lowest wealth quintile to only 1.4 percent for the top quintile. That is, the mortality rate of individuals in the poorest

\footnotetext{
${ }^{13}$ Attanasio and Hoynes use the Consumer Expenditure Survey to construct synthetic panels extending from 1982 to 1995 which they use to estimate unadjusted age-wealth profiles. The Survey of Income and Program Participation provides panel data extending over 28-month intervals that they use to estimate survival rates by wealth and age. While the panel intervals are short, the samples are very large - 21,000 families in the 1984 panel and 12,000 in 1987.
} 
quintile exceeds that of those who died in the in the richest quintile by nearly four to one! At the same time there, is no substantial correlation between wealth and attrition from the survey for other reasons.

An alternative perspective is provided in figure 8, where respondents are divided into: (1) those who participated in all seven waves of the survey, (2) those who temporarily exited but returned by 2004, (3) permanent attritors, and (4) those who died by 2006. For each group, the figure shows mean wealth holdings for the 1992 respondents in each wave of the survey if they were present. ${ }^{14}$ Surprisingly, there is very little difference in the wealth of those who leave for reason other than death and the group that has been present for all seven waves of the survey. However, respondents who died over the period of 1992 to 2006 had average wealth holdings less than 60 percent of those who remained in the survey. That difference is the source of the large negative correlation between wealth and mortality.

The seven waves of the HRS provide substantial information about the relationship between wealth and mortality that can be used to measure the magnitude of the mortality bias present in standard cross-sectional surveys. As a point of departure, the data shown in table 4 indicate that the annual mortality rates of the HRS are very similar to the U.S. life tables published by the National Center for Health Statistics. The observed rates are a bit low at the older ages, but that may reflect a lag of recording deaths in the latest waves of the HRS.

We derive a mortality correction factor for the age-wealth profile following the same procedures as Attanasio and Hoynes (2000). Our approach differs only in that we focus on individuals rather than families. Attanasio and Hoynes limited their analysis to couple families classified by the age of the head and they defined a death of the family if either member died. We focused on individuals, dividing the wealth of couples equally between the two members and combining those estimates with data on single-person households. By using all of the birth cohorts up to 1953, we have about 75 thousand observations, but the age range is limited to individuals over age 50 .

\footnotetext{
${ }^{14}$ Similar figures were constructed using respondents in waves other than 1992 to define the control group. The differences are concentrated in the category of temporary attritors who often had significantly lower wealth. However, it is often a small sub-sample with high variance.
} 
First, we estimate a logistic formulation of survival probabilities (PS) as a function of individuals' age $(a)$ and percentile of the wealth distribution ( $w p$ ) for their age cohort.

$$
P S(a, w p)=\frac{1}{1+\exp (f(a, w p))} .
$$

The results of the maximum likelihood estimation are shown in column (1) of table 5. Wealth has a highly significant positive effect on survival probabilities that is nonlinear for individuals in the lower quarter of the wealth distribution. If the relationship is expanded to include other categorical variables (column 2), gender, years of schooling and marital status have highly significant effects while the role of race is more marginal. ${ }^{15}$ But they all have only modest effects on the wealth and age coefficients. Because the coefficients on wealth and age can be somewhat difficult to interpret, the implied mortality rates for the equation without the categorical variables are shown graphically in figure 9. The effects of wealth on survival probabilities is greatly magnified in the lower portions of the wealth distribution, and the probability of death is about 4 times higher for a person in the $10^{\text {th }}$ percentile of the age distribution, compared to a person at the $90^{\text {th }}$ percentile. ${ }^{16}$ The magnitude of the correlation between wealth and mortality suggests that the mortality bias identified by Shorrocks may be substantial.

Attanasio and Hoynes (2000) used a similar estimate of the relationship between mortality and age to adjust a cross-sectional age-wealth profile for the progressive underrepresentation of low-wealth households. One major complication is that the adjustment requires a measure of the cumulative probability from some critical age at which the relationship between wealth and mortality becomes an important factor. Yet, the individual's position in the cohort's wealth distribution is not known for earlier ages. Attanasio and Hoynes assume that the rankings of wealth do not change over time and adjust only for the probability that those at a lower position in the distribution are more likely to have died in prior years. That allowed them to generate an estimate of a couple's wealth position in prior years and compute a cumulative probability of survival.

\footnotetext{
${ }^{15}$ Marital status may be significant in part because the equal division of the wealth of couples makes no allowance for economies of scale.

${ }^{16}$ The regressions are actually based on two-year survival rates from successive waves of the HRS, but they are converted to annual rates in figure 8.
} 
They were then able to reweight a cross-section sample using a correction factor equal to the reciprocal of the cumulative probability of survival. ${ }^{17}$ The procedure results in an increased weight being assigned to poorer households.

The results of applying the methodology of Attanasio and Hoynes to the HRS data are shown in table 6 . We have computed the weights at various levels of relative wealth; and, as shown in the last column, the adjustment for individuals at the $20^{\text {th }}$ percentile of the wealth distribution rises substantially more rapidly that that for an individual at the $80^{\text {th }}$ percentile. Our adjustments are smaller than those of Attanasio and Hoynes because we based the analysis on individuals rather than couples, but wealth still has a substantial effect on the relative weight, particularly after age 75 . Figure 10 shows the result of applying the adjustment to the age-wealth profile obtained from the 2004 wave of the HRS. The original data indicate a humped distribution with mean wealth rising up to age 65 and falling by about 15 percent between ages 65 and 80 . The adjustment amplifies the evidence of a decline in wealth beyond age 65 with a 25 percent drop by age 80 .

Attrition and Mortality in the PSID. A summary of the attrition and mortality experience of individuals in the PSID is shown in table 7. The analysis is based on those sample members who were present in $1984 .{ }^{18}$ As with the HRS analysis in table 4, the individual cells report the proportion of individuals in each ten-year age cohort (column) and 1984 wealth quintile that left the survey sometime between 1984 and 2005. The first finding is that the PSID has experienced a higher rate of attrition than the HRS, even allowing for the fact that the analysis extends over 22 years. Second, there is less evidence of a strong inverse correlation between wealth and mortality. Overall, the mortality rate in the bottom wealth quintile is a bit more than twice that of the top quintile, but below the 4:1 ratio observed in the HRS. In part, the weaker effect can be traced to a wider age distribution in the PSID sample; but we also find that the mortality rates of the PSID are below those of the U.S. life tables. We suspect that there are larger

\footnotetext{
${ }^{17}$ The details of the adjustments are described in their 2000 paper.

${ }^{18}$ Individuals are defined as sample members if they are members of an original 1968 sample household or if they are descendants of an original household member. Those who join the household through marriage have no individual weight and are excluded.
} 
problems with the up-to-date recording of deaths in the PSID - particularly for those who left the survey after 1984.

Mean and median wealth holdings over the seven waves of the PSID that provide wealth information are shown in figure 10. As with the HRS, respondents are divided into those who participated in all seven waves, those who temporarily exited but returned by 2005, permanent attritors, and those who died. There are some significant differences relative to the HRS. First, there is more evidence that persons who exit the survey have lower prior levels of wealth. That seems particularly true for those who exit temporarily, but that finding is based on a very small sub-sample. The wealth holdings of permanent attritors are estimated from a larger sub-sample, however, and the magnitude of the difference relative to the wealth of continuous participants appears to be growing over time. Second, there is less evidence that those who died after 1984 had lower wealth holdings compared to the results for the HRS. It is important to note, however, that the data from the PSID are based on a much wider age distribution and the sample size quickly becomes too small to make comparisons that control for age differences.

A more precise measure of the relationship between mortality and relative wealth can be obtained by estimating the same logit equations of survival probabilities that was done with the HRS. Those estimates are shown in columns (3)-(6) of table 5. ${ }^{19}$ One set of regressions reports the relationship for all ages, while the second set limits the sample to those over age 50 in order to correspond more closely to the HRS cohorts. In addition, one version relates the survival probabilities solely to age and relative position in the wealth distribution, and a second estimate includes other demographic variables. In all cases, wealth is a highly significant predictor of survival rates, but there is less evidence than with the HRS of a strong nonlinearity for those in the lower ranges of the wealth distribution. Overall, mortality bias is a significant feature of both the PSID and the HRS, but the larger sample size of the HRS generates more exact estimates of its magnitude.

\footnotetext{
${ }^{19}$ One complication of the PSID is that the interval between the waves varies from five years in the 1984-99 period to two years after 1999. For the regressions shown in table 6, we dropped the 2001 and 2002 waves and combined the data from the 6-year span from 1999 to 2004 together with the pre-1999 data. A second alternative was to estimate separate regressions for the pre- and post-1999 data. The results from both methods were very similar.
} 


\section{Saving and Wealth Changes}

For many purposes, researchers are content to use estimates of the stock of wealth from household surveys. By enabling greater future consumption, wealth is an important element of economic well-being, but it may matter little how the households accumulated it. However, in order to understand the process of wealth accumulation it is critical to be able to distinguish between wealth changes due to decisions to forego consumption and

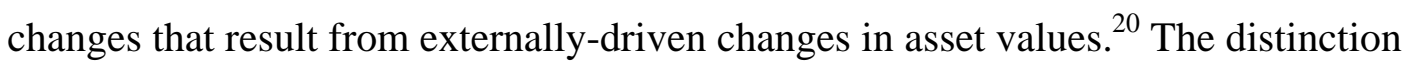
between price changes and saving is particularly important at the level of the aggregate economy because of the role of saving in the financing of the nation's investment and the link between the saving-investment balance and external trade. In understanding the causes and consequences of reduced saving, it would be useful to know whose saving has fallen and is it a general phenomenon or one limited to a few socio-economic groups? That question can be answered only within a micro-level survey of household saving.

Both the SCF and the PSID have been used in prior studies aimed at exploring the decline in saving. Several researchers have attempted to construct synthetic cohorts from the successive waves of the SCF and to use that data to estimate saving and wealth changes for various groups. ${ }^{21}$ However, the method is limited to household groups whose characteristics remain fixed over time - age gender, race, and perhaps educational attainment. Saving is known to be highly heterogeneous across household groups, yet the SCF is a relatively small survey in which estimates for subgroups quickly become unstable. There is also significant variation in the composition of households due to marriage, divorce and death - all factors with major effects on the dynamics of wealth change. Finally, the method relies on external estimates of asset prices to divide the wealth changes between saving and valuation changes.

\footnotetext{
${ }^{20}$ For example, an increase in housing wealth resulting from higher home values is different than an increase due to a rise in the number of homes. Higher prices will increase the welfare of older households (owners) at the expense of losses for the young (buyers). In contrast, an increase in the number of homes does not impose offsetting losses.

${ }^{21}$ The basic methodology is outlined in Deaton (1985). Recent examples of its application to estimates of saving are Sabelhaus and Pence (1999), Bosworth and Bell (2005) and Sabelhaus and Schwabish (2006).
} 
The major advantage of the PSID is that it is a longitudinal survey that provides direct estimates of the change in wealth and saving. Hurst and others (1998) used data on wealth accumulation in the PSID between 1984 and 1994 to demonstrate the heterogeneity of family saving behavior and the dominant role of capital gains in accounting for the wealth accumulation of individual families. Juster and others (2006) analyze the same family-level data on saving and wealth accumulation for 1984-89 and 1989-94. They argue that capital gains on equities, not housing, have been the primary contributor to the decline in the personal saving rate at the national level. In the following sections we extend this work to cover later waves of the PSID and the HRS. ${ }^{22}$

SCF. The SCF provides a series of snapshots of the wealth distribution that extends over much of the period of decline in the aggregate measures of household saving; and as discussed above, it appears to track the evolution of wealth changes that are reported in the flow of funds accounts. However, it provides no direct evidence on saving. Each survey is based on a new sample and respondents are not asked retrospective questions about their wealth holdings. We have extended our prior comparison of the wealth measures of the flow of funds and the SCF to include the changes in wealth and saving. The reconciliation tables of the flow of funds allocate the aggregate change in wealth between saving and valuation changes. We used the data from the reconciliation table for the household sector to compute rates of valuation change over the intervals between successive SCF surveys separately for real estate, noncorporate business, and corporate equities. By applying the indexes of valuation change to successive waves of the SCF we can obtain estimates of saving as a residual of the change in net worth less the valuation change.

The results of the computation are reported in table 8. As noted earlier, the SCF and F/F estimates of household wealth are quite similar up through 1998 and that correspondence is reflected in the measures of changes in net wealth - in particular, both measures capture the large rise in equity-type assets in 1995-98. There is a large

\footnotetext{
${ }^{22}$ A substantial number of prior studies have made use of the wealth data from the HRS to explore the wealth holdings of households prior to retirement, but we have not encountered any study that analyzes the information on saving.
} 
discrepancy in subsequent years, however, as the SCF reports substantially higher rates of wealth accumulation through 2004. The differences are magnified for saving since the estimates of valuation change in the F/Fs are carried over to the SCF. The upshot is estimates of saving from the SCF that are uncorrelated with the F/F measures and that display no indication of a secular decline in saving.

We conclude that reliable estimates of saving and wealth changes cannot be derived from a series of independent wealth surveys. Even though the SCF is thought to be of particularly high quality, when we observe a large change in wealth - as between the 1998 and 2001 surveys - we do not know if it reflects the experience of the surveyed households or simply variation in the structure of the two surveys. The problems are even larger for the estimates of saving since we are forced to employ external measures of the valuation change that are assumed to be the same for all households. Given the lack of correspondence between the SCF and the F/Fs at the aggregate level of table 8, we do not believe that the method is an effective approach to measuring saving across various socio-economic groups.

PSID and HRS. As longitudinal surveys, the PSID and the HRS permit the direct computation of the change in wealth holdings of sampled households. The wealth and saving modules of the two questionnaires are very similar and they also enable the division of the change in wealth between two components of active and passive saving (capital gains/losses). Saving can be computed separately for the three broad components of wealth: (1) housing, (2) fixed-price assets (deposit accounts, bonds, and other debt), and (3) equity-type assets that are subject to capital gains/losses (real estate, own business and corporate equities). For those who do not move, active saving in housing is simply equal to the negative of the change in mortgage debt plus any home improvements. For movers, we add the change in the price between the new and old home. Information on the actual purchase and sale prices is available in the HRS, but we only have the reported home values from successive waves for the PSID. For the three elements of wealth subject to capital gains or losses (equities, real estate and business), the questionnaires include specific questions about asset purchases and sales (active saving). The valuation changes (passive saving) are computed as the change in net wealth minus active saving. 
By definition, there is no valuation change for fixed-price assets (transaction accounts and other assets, minus non-collateralized debt) where the saving is simply the change in the real value of the asset. Both the stocks and flows are measured in prices of 2000.

A summary of the data from the PSID is shown in table 9. The calculation of saving requires that a household be included at both the beginning and the end of a subperiod; and to reduce the influence of changes in family composition, we required them to have the same head in both periods. The number of sample households varies from a low of 4,674 in 1994-99 to a high of 6,674 in 2002-04. The first column reports the estimated average annual amount of active saving, followed by passive saving in column 2 and the annual change in wealth (active plus passive saving) in column 3 for each of the six sub-periods. ${ }^{23}$ Most notably, mean active saving does not decline over the full period. This result is equally evident if the data are scaled by income and reported as mean saving rates in column 5. Only the median saving rate, shown in the last column, provides consistent evidence of a secular decline in saving. ${ }^{24}$ The rates of wealth accumulation, however, are similar to those in the SCF over the full period of 1984 to 2004, and the PSID shows the same marked rise in the wealth-income ratio after the mid1990s. They differ only in the timing, with the PSID showing a larger portion of the gains in the late 1990s and again in 2003-05, whereas the SCF reports a particularly large increase between the 1998 and 2001 surveys.

Rates of saving and wealth accumulation for major socio-economic groups are shown in the middle of the table. The subperiods are also aggregated to focus on the 10year periods before and after 1994. Again, there is little consistent evidence of a decline in saving after 1994; but there are substantial differences in rates of saving across the groups. Rates of saving are higher for those households that own businesses or have equity holdings, and households with more educated heads also have high rates of saving. If we interpret education as a proxy for permanent or lifetime income, these results support the hypothesis that higher-income households have higher saving rates (Dynan et al, 2004). Surprisingly, there is no consistent difference in saving rates between

\footnotetext{
${ }^{23}$ The data include all households that participated in both survey years and whose household head did not change. The weights are those of the initial year.

${ }^{24}$ The saving rates are computed as a ratio of the means or medians of saving and income.
} 
homeowners and renters, although homeowners did have a very rapid rate of wealth accumulation after 1994 due to substantial capital gains. It is also notable that saving rates are substantially lower - and often negative - for households with a head over age 60 , compared to those with a head of prime working age. The allocation of saving across the three components of wealth is reported at the bottom of the table. Saving within equity-type assets does show the pattern of decline that we expected for the total, but saving within housing and fixed-price assets has increased since the mid-1990s.

A comparable set of tabulations of saving and wealth change for the HRS are shown in table 10. We restricted the analysis to the to the original HRS cohort of individuals born in the interval of 1931-41. Again, households must be in the survey at the beginning and end of a subperiod and have the same designated head in both periods. The number of sample cases ranges from 3,727 to 5,263. The estimates of mean saving per household are very similar to the magnitudes obtained from the PSID and there is some evidence of a decline in average saving rates after 1998. However, unlike the PSID, the HRS is tracking a fixed birth cohort that is transitioning into retirement over the period of observation. That is most evident in the declining levels of average income. It is also notable that capital gains account for a larger portion of the change in net worth of this older cohort. ${ }^{25}$ As with the PSID, there is a strong association between levels of education and saving rates; yet, there is less evidence of significant difference in saving rates across the other socio-economic groups.

The estimates of saving and the change in net worth for both the PSID and the HRS are quite volatile across subperiods and subgroups. In part, these problems can be traced to the small sample sizes for groups such as business owners, but the calculations are also affected by outliers in the reported values of the wealth components and active saving. Various algorithms for identifying those outliers indicate a substantial number of implausible answers to the wealth and saving questions, either due to problems in the original responses or coding errors. In some of the most egregious cases, the outlier values are very extreme relative to surrounding periods, suggesting that they must reflect data entry problems. As discussed more fully in the appendix, we did make some editing

\footnotetext{
${ }^{25}$ The same pattern of an increased role for capital gains/losses is evident in the comparable age categories of the PSID.
} 
changes in the wealth data based on a comparison with values in the prior and subsequent waves of the survey. However, that method cannot be used to edit values in the first and last waves of the survey. ${ }^{26}$ In addition, we did not make any changes in the answers to the active saving questions because there was no obvious way to establish reasonable limits on the answers.

The measurement concerns are illustrated in table 11, by reporting the distribution of saving rates for both the PSID and the HRS. The saving rate is measured as saving over each subperiod divided by income. For the PSID we have annual estimates of income that were used to compute the saving rates for both the 5-year intervals before 1999 and the 2-year spans in subsequent waves of the survey. For the 2-year spans we used the five surrounding years. The HRS reports income only for each survey year, and we used the average of income over the full 1992- 2004 period as a common denominator. The distributions of the saving rates shown in the table are averages of the six subperiods. Except for the change before and after 1999 in the PSID, the results were extremely uniform across the subperiods. The distribution of total saving is summarized in the first column and the three components are shown in columns (2) - (4). Absolute values for the saving rate in excess of unity seem implausible since they imply extreme imbalances between income and consumption. ${ }^{27}$ For the PSID, about seven percent of the observations for total saving are in the two tails of the distribution. The proportion judged to be extreme is substantially larger -about 25 percent - for the HRS. Among the components of saving, the distribution is narrowest for equity-type saving where the estimates are based on the responses to direct questions, and widest for the fixed-price assets, where saving is computed as the difference in the measures of asset holdings from two separate waves of the survey.

We re-computed the measures of average saving and wealth change in tables 9 and 10, using a variety of different methods to trim the more extreme values. They

\footnotetext{
${ }^{26}$ For example, one observation records a change in wealth from \$4 million in 2002 to \$28 million in 2004; and exclusion of that one case changes the estimate of the average annual change in net wealth of non-homeowners between 1998 and 2004 from \$48 to \$22 thousand.

${ }^{27}$ Information is available on large transfers, such as inheritance and funds associated with the movement of individual into or out of the household, but they do not appear to be a major cause of large changes in saving.
} 
included the exclusion of observations with absolute values of the saving-income ratio in excess of two, and dropping those observations that had the 10 most-extreme values for each of the individual components of saving. In general, the estimates of saving remained volatile across the six subperiods, particularly for the smaller samples; and there was no consistent influence on the estimated mean saving rates. The benefits of eliminating extremes are largely offset by significant reductions in the sample size.

Regression Analysis. The survey-based estimates of saving can also be evaluated within a regression framework that explores the family level response of saving to changes in income, prior wealth accumulation and valuation changes. A previous study by Juster and others (2006) use data from the 1984 through 1994 waves of the PSID to examine the influence of capital gains on saving. We are able to extend the data for subsequent waves of the PSID and we have applied a matching model to family-level data from the HRS. The basic model emphasizes a notion of target wealth holding in which desired wealth is a function of household income and age, and active saving in each period is aimed at closing a portion of the gap between desired wealth and actual wealth at the beginning of the period (Carroll, 1997).

$$
\begin{aligned}
& W^{*}=F(\text { Age, } \text { Income }) \\
& \text { ActSav }=\alpha\left(W^{*}-W_{-1}\right)
\end{aligned}
$$

We included a few variables, such as marital transitions and net transfers of funds into the family, that may have transitory effects on saving. We also had information on whether households had employer-provided pension accounts. Fixed-price assets are excluded from the definition of initial wealth because the change in those assets is part of the definition of active saving - introducing a negative correlation of common measurement error. For the PSID, we also followed the procedure of Juster and others (2006) to remove the top and bottom 50 values of active and passive saving for each of the wealth components as a means of reducing the influence of extreme values. For the HRS, we excluded households for whom the the absolute value of saving was greater than income.

The basic results are reported in table 12. There are two panels of results for the PSID that differentiate between the 5-year intervals between the wealth supplements for the 1984-99 waves and the two-year spans for 199-2005 A third panel presents the 
results from the analysis of the HRS. All of the regressions are based on fixed-effects estimation, and we require that a household must be included in all of the subperiods of each panel. We report 5 alternative regressions, for each panel. The first relies on a single aggregate measure of passive saving, but it introduces all of the potential measurement errors due to the linked definitions of active and passive saving. The second equation separates passive saving into three asset components. Regressions 3 through 5 show the effect of capital gains in each asset category on active saving in the other categories.

In the 1984-99 panel of the PSID, we observe that households with an employerbased pension typically save less outside the pension, though the effect appears to decline with income in 1984-99, something we do not find in the 1999-05 data set. We measure pension status as the average of the beginning and ending values for each subperiod. The variable has a value of 1 for the first pension and 1.5 if both the head and spouse have a pension. ${ }^{28}$ This status variable is only weakly identified since it does not change over the subperiods for many families. The results for the HRS indicate a negative effect of the interaction between the pension status and income. ${ }^{29}$

There is a large and consistently negative correlation with initial wealth, which we interpret as being consistent with target-saving behavior where the target for wealth is defined by income and other household characteristics. However, the size of the coefficient varies substantially across the three panels, appearing to be very large in the PSID after 1999, and small in the HRS. Income and transfers both have highly significant positive effects on saving in the PSID, but we can find no role for the measure of transfers in the HRS. ${ }^{30}$

Finally, we find a significant negative effect of capital gains on saving, but the magnitude of the effect is erratic across alternate specifications. The second column of each panel reports the result of simply disaggregating the capital gains into three

\footnotetext{
${ }^{28}$ We do not have pension information for 1994 , so we set the pension status variable equal to the 1989 value for 1989-94 and the 1999 value for the 1994-99 subperiod.

${ }^{29}$ If we exclude the pension-income interaction, the coefficient on income alone is negative.

${ }^{30}$ Because transfers are not identified in the same fashion in the PSID and the RAND version of the HRS (which we used for the bulk of our data), our measure transfers for the HRS may have be inappropriate.
} 
components. Capital gains in housing consistently show the largest negative effect. There is a positive correlation for passive saving in equities for the second panel of the PSID and a negative correlation for the HRS. Columns (3)-(5) report the results of our effort to exclude the effects of measurement error. We redefine active saving to exclude the component for which passive saving is included. In all three panels, the coefficient on capital gains in housing is drastically reduced or actually changes sign. There is also very little evidence of a consistent effect of capital gains for equities, as it again changes sign between the PSID and the HRS, The results for business and real estate are also highly variable. These are quite severe tests, since they involve the exclusion of large portions of the measure of active saving. Still, we cannot reject the hypothesis that the influence of capital gains on saving, shown in columns (1) and (2) is spurious.

Alternative Saving Measures. The measurement of saving in longitudinal surveys encounters two major problems. First, for those assets that we grouped into the category of fixed-price assets, there is no role for capital gains or losses, and saving is computed as the simple change in asset values as recorded in two adjacent waves of the survey. At present, no effort is made to condition answers to the wealth questions by reminding respondents of prior responses or to use retrospective questions. Thus, the measurement error should be independently distributed across the survey waves. In that situation, the first difference of the asset values is likely to exacerbate the role of measurement error, greatly increasing the noise-to-signal ratio. That pattern seems evident in the data where saving in the fixed-price component has the widest distribution of the three components (table 11). ${ }^{31}$ We also can observe a significant degree of negative autocorrelation in the estimates of this component of saving across subperiods.

In contrast, the measure of active saving in equity-type assets is the result of direct questions about net purchase over the subperiod. Thus, it should display a relatively tight distribution of responses. Passive saving (capital gains/losses) is

\footnotetext{
${ }^{31}$ The HRS does make an effort to ensure that the most relevant member of couple households answers the questions about finances. Relying on the same person to answer the wealth questions across successive waves would be expected reduce the measurement error in the difference. Surprisingly, however, the distribution of values in the HRS for saving in fixed-price assets is substantially broader that reported for the PSID.
} 
computed in turn as a residual of the change in asset values between two waves of the survey less active saving. However, many researchers question whether respondents can answer the questions about purchases and sales of assets in a meaningful fashion. Investors in stock for example may not keep full records of their transactions.

As a partial test of whether there is any useful informational content in the measures of active saving in equity-type assets, we computed simple fixed-effect regressions in which we related the change in the asset value over each subperiod to the measure of active saving plus an external estimate of passive saving that we computed as the change in market indexes of prices for equities and real estate scaled by the average of beginning and end-of-period asset values. ${ }^{32}$ The measures of the change in asset values and active saving are derived from independent questions and should not share any common measurement error. The results are highly significant coefficients on both the active saving and the measures of price change, but with low overall explanatory power $\mathrm{R}^{2} \mathrm{~s}$ between 0.07 and 0.14 . In part, the low correlation may be due to the fact that the national indexes do not reflect regional variations in real estate prices and variations in the composition of individual investor portfolios. The significant coefficients on the responses to the active saving questions suggest that they do provide meaningful information.

Finally, we constructed estimates of saving in equity-type assets by using the national price indexes to estimate the passive saving component and obtained active saving as a residual. This is the same method used to compute saving in the SCF, but with the advantage of estimates of beginning and ending-period asset values for each respondent. However, the saving rate estimates across subperiods and across various socio-economic groups were highly erratic. Thus, some direct measure of the active saving component appears to be crucial to obtaining meaningful measures of saving.

We conclude that the measures of saving derived from the PSID and the HRS are subject to very high levels of measurement error. In addition, it appears that significant errors are introduced either through recording errors or interviewee responses that seem

\footnotetext{
${ }^{32}$ We used calendar-year averages of the Wilshire index for equities and the index of home prices, as published by the Office of Federal Housing Enterprise Oversight, for real estate. The regressions were also based on fixed effects estimates to eliminate differences among households.
} 
inconsistent with answers from prior waves. The first type of error can be reduced by more extensive editing, but inconsistent responses raise more difficult problems. Proposals to remind the respondents of prior answers raises concerns about the distorting influence on current responses, but the reliance on computer-assisted interviewing should make it possible to add some questions at the end of the interview or in a short follow-up session to inquire about the reasons for particularly large between-wave changes.

While the information on wealth levels across waves of the survey is a significant advantage of the longitudinal surveys, meaningful estimates of saving cannot be constructed without some information on the division of wealth changes between net purchases and valuation changes. Our analysis suggests that much of the volatility in the estimates of saving can be traced to measurement errors in the levels data. We do find evidence of a significant correlation of the between-wave change in wealth values and reported net purchases for those assets that are subject to valuation changes. 


\section{References}

Attanasio, Orazio P., and Hilary W. Hoynes. 2000. "Differential Mortality and Wealth Accumulation." Journal of Human Resources 35(1): 29.

Bosworth, Barry, and Lisa Bell. 2005. "The Decline in Saving: What Can We Learn From Survey Data? Working Paper \#2005-15, Center for Retirement Research at Boston College (October).

Bosworth, Barry and Sarah Anders. 2008. "Saving and Wealth Accumulation in the PSID, 1984-2005.” Working Paper, \#2008-2, Center for Retirement Research at Boston College (March).

Carroll, Christopher. 1997. "Buffer-Stock Saving and the Life Cycle/Permanent Income Hypothesis,” Quarterly Journal of Economics, Vol. 112, No. 1: 1-55.

Curtin, Richard, F. Thomas Juster, and James Morgan. "Survey Estimates of Wealth: An Assessment of Quality.” In Robert E. Lipsey and Helen Stone Tice, eds., The Measurement of Saving, Investment, and Wealth. Chicago: University of Chicago Press, 1989.

Czajka, John L., Jonathan E. Jacobson, and Scott Cody. 2003. "Survey Estimates of Wealth: A Comparative Analysis and Review of the Survey of Income and Program Participation,” report to Social Security Administration, Office of Research, Evaluation and Statistics (August).

Deaton, Angus.1985. “Panel Data From Time Series of Cross-Sections,” Journal of Econometrics, 30:1(October-November):109-26.

Dynan, Karen, Jonathan Skinner, and Stephen Zeldes. 2004. “Do the Rich Save More?” Journal of Political Economy, 112, no 2: 397-443.

Fitzgerald, John, Peter Gottschalk, and Robert Moffitt. 1998. An Analysis of Sample Attrition in Panel Data. The Journal of Human Resources 33, no. 2: 251-99.

Hurst, Erik, Ming Ching Luoh, and Frank P. Stafford. 1998. "The Wealth Dynamics of American Families, 1984-94.” Brookings Papers on Economic Activity, 1998:1.

Juster, F. Thomas, Joseph P. Lupton, James P. Smith, and Frank Stafford. 2006. “The Decline in Household Saving and the Wealth Effect," Review of Economics and Statistics, 88(1): 20-27.

Juster, F. Thomas, James P. Smith, and Frank Stafford. 1999. “The Measurement and Structure of Household Wealth.” Labour Economics 6: 253-75.

Kapteyn, Arie, Pierre-Carl Michaud, James Smith, and Arthur van Soest. 2006 RAND working paper, WR-407 (September).

Lillard, Lee, and Constantijn W. A. Panis 1998. Panel Attrition from the Panel Study of Income Dynamics. The Journal of Human Resources 33, no. 2: 437-57. 
Sabelhaus, John, and Karen Pence. 1999. "Household Saving in the 1990s: Evidence from Cross-Section Wealth Surveys,” Review of Income and Wealth, 45, No. 4: 435-453.

Sabelhaus, John and Jonathan Schwabish. 2006. "Measuring Household-Level Saving Rates: A Synthetic Panel Approach,” Mimeo, Congressional Budget Office.

Shorrocks, Anthony F. 1975 "The age-wealth relationship: a cross-section and cohort analysis," Review of Economics and Statistics, 57(2): 155-63.

Wolff, Edward N. 1999. "The Size Distribution of Wealth in the United States: A Comparison among Recent Household Surveys.” In James P. Smith and Robert J. Willis, eds., Wealth, Work, and Health: Innovations in Measurement in the Social Sciences. Essays in Honor of F. Thomas Juster. Ann Arbor: The University of Michigan Press. 
Table 1. Mean Wealth by Uniform SCF Wealth Decile, 1989 and 2001

Thousands of 2000 dollars

\begin{tabular}{|c|rrr|rrr|}
\hline Means & SCF 1989 & PSID 1989 & \multicolumn{1}{c|}{ diff } & SCF 2001 & PSID 2001 & \multicolumn{1}{c|}{ diff } \\
\hline $0-10$ & -15.73 & -14.58 & -1.15 & -17.72 & -21.82 & 4.10 \\
10 to 20 & -0.36 & -0.27 & -0.09 & -0.90 & -0.66 & -0.25 \\
$20-30$ & 1.76 & 1.85 & -0.09 & 2.59 & 2.42 & 0.16 \\
$30-40$ & 13.21 & 13.62 & -0.41 & 17.21 & 17.06 & 0.14 \\
$40-50$ & 35.90 & 36.21 & -0.31 & 43.91 & 44.16 & -0.25 \\
$50-60$ & 65.85 & 65.02 & 0.83 & 81.68 & 81.33 & 0.35 \\
$60-70$ & 106.99 & 105.97 & 1.02 & 134.33 & 136.18 & -1.85 \\
$70-80$ & 167.76 & 171.56 & -3.80 & 232.91 & 228.53 & 4.38 \\
$80-90$ & 300.37 & 298.95 & 1.41 & 439.41 & 433.23 & 6.18 \\
$90-95$ & 590.83 & 568.79 & 22.04 & 864.69 & 853.77 & 10.92 \\
$95-100$ & $2,576.86$ & $2,011.27$ & 565.59 & $4,289.02$ & $2,971.52$ & $1,317.50$ \\
& & & & & & \\
Total & 225.62 & 149.07 & 76.55 & 349.62 & 219.83 & 129.79 \\
& & & & & & \\
PSID/SCF (up to 95) & 98.46 & & & 68.67 & & \\
PSID/SCF, percent & 66.07 & & & & & \\
\hline
\end{tabular}

Sources: PSID and SCF public-use files from 1989 and 2001, and authors' estimates.

Notes: Mean wealth of the population is shown by decile for both 1989 and 2001. Calculations are done for the entire wealth distribution as well as for only those households whose wealth holdings fall below the 95th wealth percentile ("up to 95"). The uniform percentile breakpoints in the wealth distribution are calculated from each year of the SCF using the whole population. 
Table 2. Comparison of Mean Household Wealth and Income by Educational Attainment of the Household Head of the 1931-1941 Birth Cohort from the SCF and HRS, 1992-2004

\begin{tabular}{|l|cccccc|}
\hline SCF/HRS & 1992 & $\mathbf{1 9 9 4 / 1 9 9 6}$ & $\mathbf{1 9 9 8}$ & $\mathbf{2 0 0 0 / 2 0 0 2}$ & $\mathbf{2 0 0 4}$ & Average \\
\hline $\begin{array}{r}\text { Mean Wealth } \\
\text { All households }\end{array}$ & 1.47 & 1.43 & 1.51 & 1.77 & 1.40 & 1.51 \\
Education of head & & & & & & \\
no h.s. degree & & & & & & \\
h.s. degree & 1.11 & 1.24 & 0.84 & 1.16 & 1.08 & 1.09 \\
some college & 1.30 & 1.63 & 1.27 & 1.24 & 1.34 & 1.36 \\
college degree & 1.47 & 1.62 & 1.94 & 1.90 & 1.26 & 1.64 \\
more than college degree & 1.59 & 1.91 & 1.87 & 2.49 & 1.37 & 1.85 \\
\hline Mean Income & & & & & & \\
All households & 1.15 & 1.00 & 1.16 & 1.25 & 1.15 & 1.14 \\
Education of head & & & & & & \\
no h.s. degree & 0.90 & 0.97 & 0.94 & 0.89 & 0.87 & 0.91 \\
h.s. degree & 1.00 & 1.07 & 0.91 & 1.01 & 1.08 & 1.02 \\
some college & 0.92 & 0.94 & 0.90 & 1.14 & 0.99 & 0.98 \\
college degree & 1.10 & 1.12 & 1.14 & 1.24 & 1.15 & 1.15 \\
more than college degree & 1.28 & 1.00 & 1.48 & 1.64 & 1.08 & 1.30 \\
\hline
\end{tabular}

Sources: 1992-2004 Surveys of Consumer Finances and Health and Retirement Surveys, and authors' estimates.

Notes: Mean wealth and income are shown only for surveyed households where the head of household was born between 1931 and 1941 (part of the HRS cohort). When survey years do not line up between the SCF and HRS, the wealth and income ratios are calculated by dividing the SCF value for one survey year by the average of the HRS values in the surrounding survey years. 
Table 3. Panel Attrition by Age Cohort and Wealth Quintile, 1992-2004

Percentage of 1992 sample individuals

\begin{tabular}{|c|c|c|c|c|c|c|}
\hline \multirow[b]{2}{*}{ Wealth Quintile } & \multicolumn{5}{|c|}{ BirthYear } & \multirow[b]{2}{*}{ Total } \\
\hline & $1931-32$ & 1933-34 & 1935-36 & 1937-38 & 1939-41 & \\
\hline \multicolumn{7}{|l|}{$1-20$} \\
\hline Died & 31.6 & 27.4 & 25.3 & 20.3 & 16.6 & 5.5 \\
\hline Other Attritions & 9.1 & 12.7 & 12.2 & 11.5 & 15.7 & 3.0 \\
\hline \multicolumn{7}{|l|}{$21-40$} \\
\hline Died & 22.6 & 18.1 & 14.4 & 11.8 & 11.3 & 3.2 \\
\hline Other Attritions & 16.2 & 15.8 & 14.2 & 14.3 & 16.8 & 3.4 \\
\hline \multicolumn{7}{|l|}{$41-60$} \\
\hline Died & 17.5 & 15.0 & 11.9 & 10.9 & 8.3 & 2.4 \\
\hline Other Attritions & 17.8 & 17.3 & 16.6 & 15.0 & 15.0 & 3.2 \\
\hline \multicolumn{7}{|l|}{$61-80$} \\
\hline Died & 12.2 & 12.2 & 8.3 & 9.3 & 8.6 & 1.8 \\
\hline Other Attritions & 14.2 & 12.9 & 19.1 & 16.6 & 17.4 & 3.0 \\
\hline \multicolumn{7}{|l|}{ 81-100 } \\
\hline Died & 12.3 & 13.6 & 7.7 & 5.2 & 5.3 & 1.4 \\
\hline Other Attritions & 18.7 & 16.9 & 14.7 & 20.7 & 19.3 & 3.1 \\
\hline \multicolumn{7}{|l|}{ Total } \\
\hline Died & 20.1 & 17.8 & 14.4 & 12.1 & 10.4 & 14.3 \\
\hline Other Attritions & 14.9 & 15.0 & 15.2 & 15.3 & 16.8 & 15.6 \\
\hline Count & 1,647 & 1,656 & 1,727 & 1,849 & 2,874 & 9,753 \\
\hline
\end{tabular}

Sources: 1992-2004 Health and Retirement Surveys, 2006 HRS Tracker File, and authors' estimates.

Notes: Calculations use HRS families with the head of household born between 1931-1941 and reported wealth in 1992. The tabulations are based on individuals, with the wealth of couple households split equally between the head and spouse. The 1992 wealth distribution is done separately for each age cohort. Other attritions are defined as those who report a wealth value in 1992 but are out of the survey by 2004 for reasons other than death. 
Table 4. Mortality Rates by Age and Sex, Comparison of 1992-2004 HRS to U.S. Life Tables

\begin{tabular}{|c|c|c|c|c|c|}
\hline & & HRS & & Life & les \\
\hline Age & Survey Period & $\mathrm{N}$ & Observed Rate & 1990 & 2000 \\
\hline Total Populati & & & & & \\
\hline $50-61$ & 1992-1994 & 9,750 & $0.75 \%$ & $0.80 \%$ & $0.69 \%$ \\
\hline $52-63$ & 1994-1996 & 8,827 & $0.93 \%$ & $0.95 \%$ & $0.82 \%$ \\
\hline $54-65$ & 1996-1998 & 8,449 & $1.03 \%$ & $1.12 \%$ & $0.97 \%$ \\
\hline $56-67$ & $1998-2000$ & 8,161 & $1.39 \%$ & $1.33 \%$ & $1.15 \%$ \\
\hline $58-69$ & $2000-2002$ & 7,700 & $1.77 \%$ & $1.56 \%$ & $1.36 \%$ \\
\hline $60-71$ & $2002-2004$ & 7,448 & $1.28 \%$ & $1.82 \%$ & $1.60 \%$ \\
\hline $62-73$ & 2004-2006 & 7,089 & $1.75 \%$ & $2.13 \%$ & $1.88 \%$ \\
\hline Women & & & & & \\
\hline $50-61$ & $1992-1994$ & 9,750 & $0.58 \%$ & $0.58 \%$ & $0.52 \%$ \\
\hline $52-63$ & 1994-1996 & 8,827 & $0.58 \%$ & $0.70 \%$ & $0.63 \%$ \\
\hline $54-65$ & 1996-1998 & 8,449 & $0.87 \%$ & $0.83 \%$ & $0.76 \%$ \\
\hline $56-67$ & $1998-2000$ & 8,161 & $1.04 \%$ & $0.98 \%$ & $0.90 \%$ \\
\hline $58-69$ & $2000-2002$ & 7,700 & $1.42 \%$ & $1.15 \%$ & $1.07 \%$ \\
\hline $60-71$ & $2002-2004$ & 7,448 & $0.81 \%$ & $1.36 \%$ & $1.26 \%$ \\
\hline $62-73$ & $2004-2006$ & 7,089 & $1.46 \%$ & $1.60 \%$ & $1.49 \%$ \\
\hline Men & & & & & \\
\hline $50-61$ & $1992-1994$ & 4,592 & $0.93 \%$ & $1.12 \%$ & $0.86 \%$ \\
\hline $52-63$ & 1994-1996 & 4,091 & $1.31 \%$ & $1.33 \%$ & $1.02 \%$ \\
\hline $54-65$ & 1996-1998 & 3,898 & $1.20 \%$ & $1.58 \%$ & $1.21 \%$ \\
\hline $56-67$ & $1998-2000$ & 3,773 & $1.79 \%$ & $1.86 \%$ & $1.43 \%$ \\
\hline $58-69$ & $2000-2002$ & 3,550 & $2.15 \%$ & $2.19 \%$ & $1.68 \%$ \\
\hline $60-71$ & $2002-2004$ & 3,408 & $1.82 \%$ & $2.56 \%$ & $1.98 \%$ \\
\hline 62-73 & 2004-2006 & 3,209 & $2.09 \%$ & $3.00 \%$ & $2.33 \%$ \\
\hline $\begin{array}{l}\text { Sources: } 199 \\
\text { Life Tables, a } \\
\text { Notes: Morta } \\
\text { HRS, a one-y } \\
\text { number of pe } \\
\text { the first surve }\end{array}$ & $\begin{array}{l}4 \text { Health and } R \\
\text { hors' estimates } \\
\text { tes represent th } \\
\text { ath probability } \\
\text { ho die between } \\
\text { at age. }\end{array}$ & $\begin{array}{l}\text { orobab } \\
\text { salcula } \\
\text { /O surv }\end{array}$ & $\begin{array}{l}\text { of death over a } \\
\text { by taking the squ } \\
\text { at a given age t }\end{array}$ & $\begin{array}{l}\text { year per } \\
\text { root of } t \\
\text { those } w\end{array}$ & $\begin{array}{l}\text { NCHS } \\
\text { For the } \\
\text { tio of the } \\
\text { spond in }\end{array}$ \\
\hline
\end{tabular}


Table 5. Estimates of Survival Rate Regressions for Individuals in the 1992-2004 HRS and 1984-2005 PSID

\begin{tabular}{|c|c|c|c|c|c|c|}
\hline \multicolumn{7}{|c|}{ Dependent variable: Survived until the end of the period } \\
\hline & \multicolumn{2}{|c|}{ HRS } & \multicolumn{2}{|c|}{ PSID } & \multicolumn{2}{|c|}{ PSID (all ages) } \\
\hline & $(1)$ & $(2)$ & (3) & (4) & (5) & $(6)$ \\
\hline \multirow[t]{2}{*}{ WP } & $1.01^{* * *}$ & $0.86^{* * *}$ & $1.08^{* * *}$ & $0.88^{* * *}$ & $1.17^{* * *}$ & $0.89^{* * *}$ \\
\hline & $(0.09)$ & $(0.10)$ & $(0.19)$ & $(0.20)$ & $(0.18)$ & $(0.19)$ \\
\hline \multirow[t]{2}{*}{$W P \leq .25$} & $-0.27^{* *}$ & $-0.31^{* * *}$ & -0.15 & -0.092 & -0.21 & -0.10 \\
\hline & $(0.09)$ & $(0.09)$ & $(0.16)$ & $(0.16)$ & $(0.14)$ & $(0.14)$ \\
\hline \multirow[t]{2}{*}{$W P \leq .25 * W P$} & 0.88 & 1.06 & 0.29 & 0.013 & 0.20 & -0.17 \\
\hline & $(0.61)$ & $(0.61)$ & $(0.76)$ & $(0.77)$ & $(0.66)$ & $(0.67)$ \\
\hline \multirow[t]{2}{*}{ Age } & 0.02 & 0.02 & $-0.14^{* * *}$ & $-0.12^{\star *}$ & $-0.052^{* * *}$ & $-0.054^{* * *}$ \\
\hline & $(0.02)$ & $(0.02)$ & $(0.04)$ & $(0.04)$ & $(0.01)$ & $(0.01)$ \\
\hline \multirow[t]{2}{*}{ Age squared } & $-0.00089^{* * *}$ & $-0.00088^{* * *}$ & 0.0003 & 0.00018 & $-0.00034^{* *}$ & $-0.00032^{* *}$ \\
\hline & $(0.00)$ & $(0.00)$ & $(0.00)$ & $(0.00)$ & $(0.00)$ & $(0.00)$ \\
\hline \multirow[t]{2}{*}{ Constant } & $5.34^{* * *}$ & $5.16^{* * *}$ & $9.67^{* * *}$ & $9.03^{* * *}$ & $6.57^{* \star *}$ & $6.65^{* *}$ \\
\hline & $(0.84)$ & $(0.88)$ & $(1.37)$ & $(1.40)$ & $(0.38)$ & $(0.41)$ \\
\hline \multirow[t]{2}{*}{ Education } & & $-0.078^{* * *}$ & & $0.030^{*}$ & & $0.030 * *$ \\
\hline & & $(0.02)$ & & $(0.01)$ & & $(0.01)$ \\
\hline \multirow[t]{2}{*}{ Education squared } & & $0.0045^{* * *}$ & & $-0.00028^{* *}$ & & $-0.00028^{* *}$ \\
\hline & & $(0.00)$ & & $(0.00)$ & & $(0.00)$ \\
\hline \multirow[t]{2}{*}{ Male } & & $-0.48^{* * *}$ & & $-0.65^{* * *}$ & & $-0.72^{* * *}$ \\
\hline & & $(0.04)$ & & $(0.07)$ & & $(0.06)$ \\
\hline \multirow[t]{2}{*}{ Black } & & -0.10 & & $-0.21^{*}$ & & $-0.33^{* * *}$ \\
\hline & & $(0.06)$ & & $(0.08)$ & & $(0.07)$ \\
\hline \multirow[t]{2}{*}{ Other Ethnicity } & 1 & 0.21 & & 0.43 & & 0.19 \\
\hline & & $(0.12)$ & & $(0.42)$ & & $(0.35)$ \\
\hline \multirow[t]{2}{*}{ Married } & & $0.62^{* *}$ & & $0.21^{* *}$ & & $0.36^{\star \star \star}$ \\
\hline & & $(0.23)$ & & $(0.08)$ & & $(0.07)$ \\
\hline Observations & 75,188 & 75,159 & 10,532 & 10,532 & 35,318 & 35,318 \\
\hline Log likelihood & $-12,407.98$ & $-12,299.47$ & $-3,325.59$ & $-3,275.14$ & $-4,607.14$ & $-4,521.67$ \\
\hline
\end{tabular}

Sources: 1992-2004 Health and Retirement Surveys, 2006 HRS Tracker File, 1984-2005 Panel Studies of Income Dynamics, and authors' estimates.

Notes: Logit regression results are presented with standard errors in parentheses. ${ }^{* \star *} p<0.001,{ }^{* *} p<0.01$, ${ }^{*} p<0.05$. The tabulations are based on individuals, with the wealth of couple households split equally between the head and spouse. WP is calculated separately for each age group and survey year. In the regression, WP takes on a value between 0 and 1. Education is measured as years of schooling. Attritors (due to reasons other than death) are excluded from the regression. Regressions 1-4 are for only those individuals aged 50 and older, while for regressions 5 and 6 we use the entire available age distribution from the PSID. For the PSID, we combine the 1999-2005 surveys and use the 1984-1999 surveys to use 5- and 6-year periods to calculate the survival probabilities.

1 "Other Ethnicity" in the PSID is specifically designated as those of Latino(a) origin, whereas in the HRS this is not specified. 
Table 6. Reweighting Factor for Individuals over Age 50 at Selected Ages and Wealth Percentiles in the Health and Retirement Surveys, 1992-2004

\begin{tabular}{|c|c|c|c|c|c|}
\hline \multirow[b]{2}{*}{ Age } & \multicolumn{4}{|c|}{ Wealth Percentile } & \multirow{2}{*}{$\begin{array}{c}\text { Ratio } \\
\text { 20th/80th }\end{array}$} \\
\hline & 20th & 40th & 60th & 80th & \\
\hline 50 & 1.0063 & 1.0047 & 1.0038 & 1.0031 & 1.0031 \\
\hline 55 & 1.0394 & 1.0293 & 1.0239 & 1.0196 & 1.0195 \\
\hline 60 & 1.0989 & 1.0732 & 1.0596 & 1.0487 & 1.0479 \\
\hline 65 & 1.1945 & 1.1429 & 1.1158 & 1.0943 & 1.0916 \\
\hline 70 & 1.3588 & 1.2611 & 1.2100 & 1.1702 & 1.1611 \\
\hline 75 & 1.6661 & 1.4779 & 1.3800 & 1.3061 & 1.2756 \\
\hline 80 & 2.2883 & 1.9204 & 1.7181 & 1.5727 & 1.4550 \\
\hline 85 & 3.8735 & 2.9719 & 2.4909 & 2.1693 & 1.7856 \\
\hline
\end{tabular}

Sources: 1992-2004 Health and Retirement Surveys, 2006 HRS Tracker File, and authors' estimates.

Notes: The tabulations are based on individuals from the AHEAD and HRS cohorts where the respondent is 50 years or older. The wealth of couple households is split equally between the head and spouse. Wealth percentile is calculated separately for each age group and survey year. Reweighting factor is calculated from cumulative survival probability estimates based on Regression (1) from Table 5. 
Table 7. Panel Attrition by Age Cohort and Wealth Quintile, 1983-2005 percentage of 1984 sample individuals

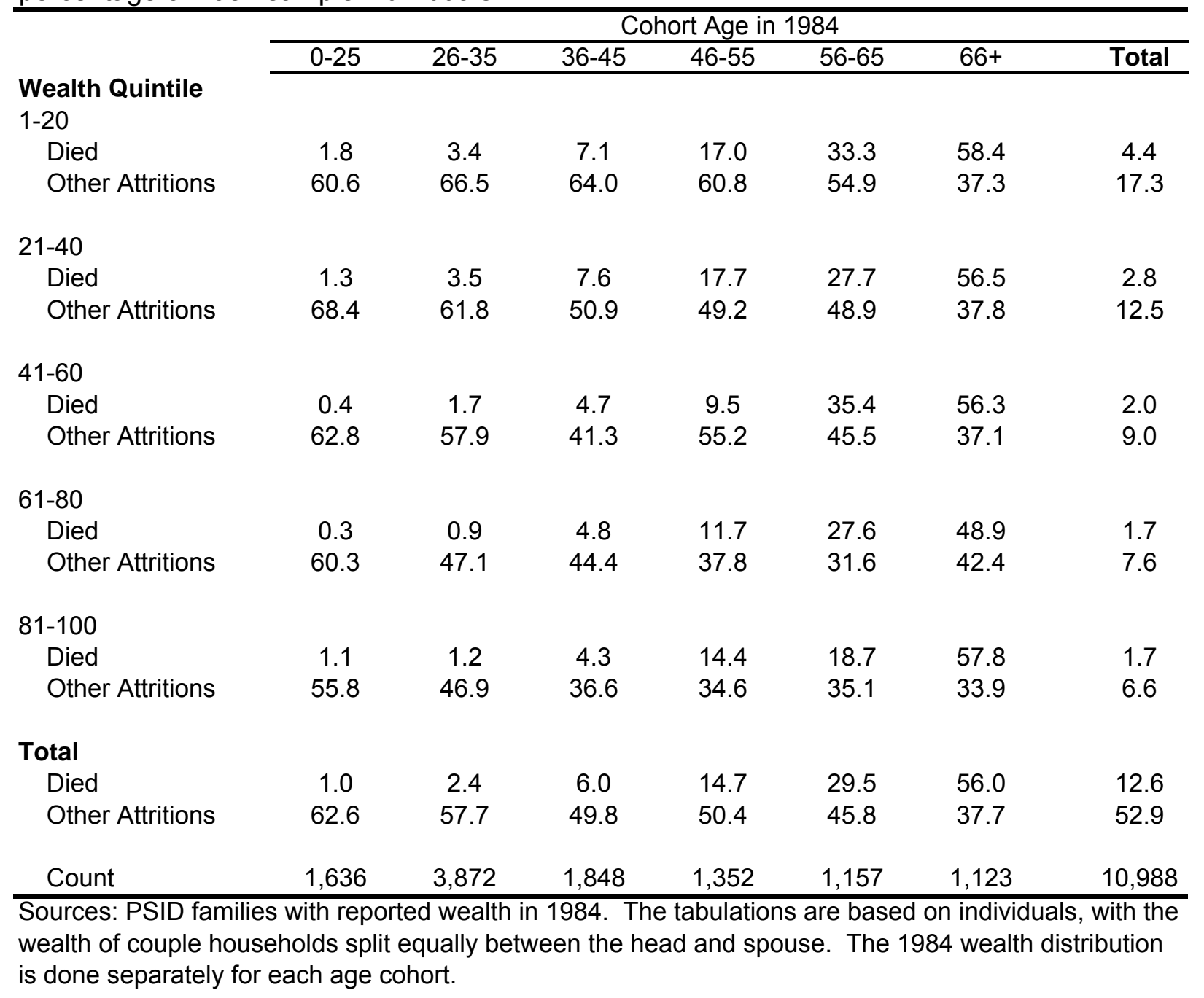


Table 8. Household Saving and the Change in Net Worth, 1983-2004

Billion of 2000 dollars

\begin{tabular}{llllll}
$1983-89$ & $1989-92$ & $1992-95$ & $1995-98$ & $1998-01$ & $2001-04$ \\
\hline
\end{tabular}

Flow of Funds

Change in Wealth

\begin{tabular}{lrrrrrr} 
Owner-occupied Real Estate & 2,522 & -107 & 413 & 1,201 & 2,953 & 3,853 \\
Home Mortgages & $-1,100$ & -423 & -341 & -501 & -910 & $-1,809$ \\
Equity-type Wealth & 1,220 & 504 & 1,828 & 5,023 & 711 & 314 \\
Fixed-price Wealth & 3,524 & 203 & 81 & 683 & 429 & 1,341 \\
\multicolumn{1}{l}{ Total } & 6,167 & 178 & 1,980 & 6,406 & 3,184 & 3,699
\end{tabular}

\section{Survey of Consumer Finances}

Owner-occupied Real Estate

Home Mortgages

Equity-type Wealth

Fixed-price Wealth

Total

$\begin{array}{rrrrrr}1,464 & -351 & 206 & 1,763 & 2,979 & 4,838 \\ -24 & -377 & -321 & -713 & -701 & -1,862 \\ 2,841 & -348 & 993 & 5,016 & 5,554 & 1,980 \\ 1,031 & -885 & 426 & 730 & 2,290 & -776 \\ 5,359 & -1,206 & 1,945 & 8,223 & 11,524 & 7,903\end{array}$

Flow of Funds

Owner-occupied Real Estate

Home Mortgages

Equity-type Wealth

Fixed-price Wealth

Total

5,359

$-1,206$

Saving

$\begin{array}{rrrrrr}1,194 & 464 & 552 & 618 & 758 & 991 \\ -1,100 & -423 & -341 & -501 & -910 & -1,809 \\ -464 & 286 & 319 & -99 & -1,029 & 28 \\ 3,524 & 203 & 81 & 683 & 429 & 1,341 \\ 3,154 & 531 & 611 & 700 & -752 & 552\end{array}$

Survey of Consumer Finances

Owner-occupied Real Estate

Home Mortgages

Equity-type Wealth

Fixed-price Wealth

\begin{tabular}{rrrrrr}
-86 & 111 & 304 & 1,313 & 1,030 & 2,148 \\
-24 & -377 & -321 & -713 & -701 & $-1,862$ \\
$-1,270$ & $-1,241$ & -679 & 349 & 3,241 & 303 \\
1,031 & -885 & 426 & 730 & 2,290 & -776 \\
-350 & $-2,391$ & -270 & 1,679 & 5,860 & -188 \\
\hline
\end{tabular}

Total

$-350-2,391$

Source: Computed by the authors from the F/Fs and the SCF as explained in the text. Saving equals the change in net worth less capital gains/losses. 
Table 9. Household Saving and Wealth Accumulation by Socio-Economic Group, PSID, 1984-2004 Average annual values per household, constant 2000 prices

\begin{tabular}{|c|c|c|c|c|c|c|c|c|}
\hline Period & $\begin{array}{l}\text { Active } \\
\text { Saving }\end{array}$ & $\begin{array}{c}\text { Passive } \\
\text { Saving } \\
\end{array}$ & $\begin{array}{c}\text { Change in } \\
\text { Wealth }\end{array}$ & $\begin{array}{l}\text { Annual } \\
\text { Income }\end{array}$ & $\begin{array}{c}\text { Active Saving } \\
\text { Rate (percent } \\
\text { of income) }\end{array}$ & $\begin{array}{c}\text { Wealth } \\
\text { Accumulation } \\
\text { Rate (percent } \\
\text { of income) } \\
\end{array}$ & $\begin{array}{l}\text { Median Active } \\
\text { Saving Rate } \\
\text { (percent of } \\
\text { income) }\end{array}$ & Transfers \\
\hline 1984-89 & 3.4 & 4.5 & 7.9 & 51.6 & 6.7 & 15.4 & 2.6 & 1.4 \\
\hline $1989-94$ & 4.4 & 0.9 & 5.4 & 53.4 & 8.3 & 10.1 & 1.6 & 0.5 \\
\hline 1994-99 & 6.0 & 5.1 & 11.1 & 59.1 & 10.2 & 18.8 & 2.4 & 0.7 \\
\hline 1999-01 & 6.0 & 8.1 & 14.1 & 59.7 & 10.0 & 23.5 & 1.7 & 1.2 \\
\hline 2001-03 & 4.4 & 0.4 & 4.8 & 59.8 & 7.4 & 8.1 & 0.8 & 2.0 \\
\hline 2003-05 & 9.0 & 15.2 & 24.2 & 62.6 & 14.3 & 38.6 & 0.9 & -1.3 \\
\hline 1984-94 & 4.0 & 2.6 & 6.6 & 52.6 & 7.5 & 12.6 & 2.1 & 1.0 \\
\hline \multirow[t]{4}{*}{ 1994-05 } & 7.1 & 7.6 & 14.7 & 60.5 & 11.8 & 24.3 & 1.7 & 0.6 \\
\hline & \multicolumn{3}{|c|}{ Saving Rate (\% of income) } & & & \multicolumn{3}{|c|}{ Wealth Accumulation (\% of income) } \\
\hline & \multicolumn{3}{|c|}{ Age } & & & \multicolumn{3}{|c|}{ Age } \\
\hline & $25-39$ & $40-59$ & $60+$ & & & $25-39$ & $40-59$ & $60+$ \\
\hline $1984-1994$ & 11.7 & 8.5 & -5.1 & & & 15.5 & 12.9 & 4.0 \\
\hline \multirow[t]{3}{*}{$1994-2005$} & 12.0 & 11.1 & 7.3 & & & 26.8 & 23.9 & 11.5 \\
\hline & \multicolumn{2}{|c|}{ Educational Attainment } & & & & \multicolumn{2}{|c|}{ Educational Attainment } & \\
\hline & $\begin{array}{c}\text { high school } \\
\text { or less } \\
\end{array}$ & $\begin{array}{c}\text { beyond high } \\
\text { school } \\
\end{array}$ & & & & $\begin{array}{c}\text { high school or } \\
\text { less }\end{array}$ & $\begin{array}{c}\text { beyond high } \\
\text { school }\end{array}$ & \\
\hline $1984-1994$ & 5.6 & 9.1 & & & & 4.3 & 15.9 & \\
\hline \multirow[t]{3}{*}{ 1994-2005 } & 5.6 & 13.0 & & & & 16.0 & 25.2 & \\
\hline & \multicolumn{2}{|c|}{ Home Owners } & & & & \multicolumn{2}{|c|}{ Home Owners } & \\
\hline & yes & no & & & & yes & no & \\
\hline $1984-1994$ & 12.4 & 8.9 & & & & 12.4 & 13.1 & \\
\hline \multirow[t]{3}{*}{ 1994-2005 } & 10.5 & 10.6 & & & & 24.3 & 13.5 & \\
\hline & \multicolumn{2}{|c|}{ Business Owners } & & & & \multicolumn{2}{|c|}{ Business Owners } & \\
\hline & yes & no & & & & yes & no & \\
\hline $1984-1994$ & 13.4 & 6.2 & & & & 12.3 & 12.6 & \\
\hline \multirow[t]{3}{*}{ 1994-2005 } & 16.3 & 9.3 & & & & 4.9 & 25.9 & \\
\hline & \multicolumn{2}{|c|}{ Equity Holders } & & & & \multicolumn{2}{|c|}{ Equity Holders } & \\
\hline & yes & no & & & & yes & no & \\
\hline $1984-1994$ & 10.0 & 5.6 & & & & 15.6 & 10.2 & \\
\hline \multirow[t]{3}{*}{ 1994-2005 } & 14.5 & 6.8 & & & & 22.6 & 21.6 & \\
\hline & \multicolumn{3}{|c|}{$\begin{array}{c}\text { Components of Active Saving: } \\
\text { (thousands of } 2000 \$ \text { ) }\end{array}$} & & & \multicolumn{3}{|c|}{$\begin{array}{l}\text { Components of Change in Net Worth: } \\
\text { (thousands of } 2000 \$ \text { ) }\end{array}$} \\
\hline & Equity-type & Housing & Fixed-price & & & Equity-type & Housing & Fixed-price \\
\hline $1984-89$ & 2.2 & 1.4 & -0.1 & & & 4.7 & 3.3 & -0.1 \\
\hline $1989-94$ & 3.1 & 1.4 & -0.1 & & & 5.3 & 0.2 & -0.1 \\
\hline $1994-99$ & 2.0 & 1.4 & 2.6 & & & 6.0 & 2.5 & 2.6 \\
\hline 1999-01 & 1.3 & 2.4 & 2.4 & & & 6.6 & 5.1 & 2.4 \\
\hline 2001-03 & 1.7 & 2.1 & 0.7 & & & -2.3 & 6.4 & 0.7 \\
\hline 2003-05 & 1.9 & 3.8 & 3.3 & & & 9.3 & 11.6 & 3.3 \\
\hline
\end{tabular}

Source: PSID data set and authors' calculations as described in text. 
Table 10. Household Saving and Wealth Accumulation, HRS Cohort, 1992-2004

Average annual values per household, constant 2000 prices

\begin{tabular}{|c|c|c|c|c|c|c|c|c|}
\hline Period & $\begin{array}{l}\text { Active } \\
\text { Saving }\end{array}$ & $\begin{array}{c}\text { Passive } \\
\text { Saving }\end{array}$ & $\begin{array}{c}\text { Change in } \\
\text { Wealth }\end{array}$ & $\begin{array}{l}\text { Annual } \\
\text { Income }\end{array}$ & $\begin{array}{c}\text { Active } \\
\text { Saving Rate } \\
\text { (percent of } \\
\text { income) }\end{array}$ & $\begin{array}{c}\text { Wealth } \\
\text { Accumulation } \\
\text { Rate (percent } \\
\text { of income) }\end{array}$ & $\begin{array}{c}\text { Median } \\
\text { Active } \\
\text { Saving Rate } \\
\text { (percent of } \\
\text { income) }\end{array}$ & Transfers \\
\hline 1992-1994 & 6.0 & 2.8 & 8.8 & 60.8 & 9.8 & 14.4 & 3.6 & 1.7 \\
\hline 1994-1996 & 4.9 & 2.3 & 7.2 & 64.2 & 7.6 & 11.2 & 0.8 & 1.3 \\
\hline $1996-1998$ & 4.8 & 14.3 & 19.1 & 63.5 & 7.5 & 30.0 & 1.0 & 2.5 \\
\hline $1998-2000$ & 2.7 & 16.1 & 18.9 & 62.6 & 4.4 & 30.1 & 1.3 & 2.6 \\
\hline $2000-2002$ & 5.6 & -21.8 & -16.3 & 60.4 & 9.3 & -26.9 & 1.6 & 1.9 \\
\hline 2002-2004 & 4.6 & 28.6 & 33.2 & 58.3 & 8.0 & 57.0 & 1.5 & 3.5 \\
\hline $1992-1998$ & 5.3 & 6.6 & 11.8 & 62.7 & 8.4 & 18.9 & 2.0 & 1.9 \\
\hline $1998-2004$ & 4.3 & 7.9 & 12.2 & 60.4 & 7.1 & 20.1 & 1.5 & 2.7 \\
\hline
\end{tabular}

1992-1998

1998-2004

1992-1998

1998-2004

1992-1998

$1998-2004$

1992-1998

1998-2004
Saving Rate (percent of income)

Educational Attainment

\begin{tabular}{cc}
\hline $\begin{array}{c}\text { high school } \\
\text { or less }\end{array}$ & $\begin{array}{c}\text { beyond high } \\
\text { school }\end{array}$ \\
\hline 5.8 & 11.4 \\
5.1 & 9.4
\end{tabular}

\begin{tabular}{cc}
\multicolumn{2}{c}{ Home } \\
\hline yes & no \\
\hline 8.6 & 6.9 \\
5.8 & 21.2
\end{tabular}

Business Owners

\begin{tabular}{cc}
\hline yes & no \\
\hline 3.8 & 9.9 \\
10.1 & 6.4
\end{tabular}

\begin{tabular}{cc}
\multicolumn{2}{c}{ Equity Holders } \\
\hline yes & no \\
\hline 10.9 & 6.0 \\
7.0 & 7.2
\end{tabular}

Components of Active Saving: (thousands of $2000 \$$ )

\begin{tabular}{|c|c|c|c|}
\hline & Equity-type & Housing & Fixed-price \\
\hline 1992-1994 & 1.1 & 2.1 & 2.8 \\
\hline 1994-1996 & 3.2 & 4.1 & -2.5 \\
\hline 1996-1998 & 1.2 & 1.1 & 2.5 \\
\hline $1998-2000$ & 0.5 & 2.2 & 0.0 \\
\hline $2000-2002$ & 1.6 & 2.3 & 1.6 \\
\hline $2002-2004$ & 1.1 & 1.5 & 2.0 \\
\hline
\end{tabular}

\section{Wealth Accumulation (percent of income)}

Educational Attainment high school or beyond high

\begin{tabular}{cc} 
less & school \\
\hline 16.2 & 22.0 \\
4.0 & 38.1
\end{tabular}

\begin{tabular}{|c|c|}
\hline \multicolumn{2}{|c|}{ Home Ownership } \\
\hline yes & no \\
\hline 20.4 & 6.9 \\
\hline 17.4 & 48.3 \\
\hline
\end{tabular}

\begin{tabular}{|c|c|}
\hline \multicolumn{2}{|c|}{ Business Owners } \\
\hline yes & no \\
\hline-1.7 & 25.7 \\
\hline-30.0 & 33.4 \\
\hline
\end{tabular}

\begin{tabular}{cc}
\multicolumn{2}{c}{ Equity Holders } \\
\hline yes & no \\
\hline 21.0 & 16.4 \\
20.0 & 18.5
\end{tabular}

Components of Change in Net Worth: (thousands of 2000 \$)

\begin{tabular}{ccc}
\hline Equity-type & Housing & Fixed-price \\
8.0 & -2.0 & 2.8 \\
8.2 & 1.5 & -2.5 \\
11.8 & 4.7 & 2.5 \\
16.2 & 2.6 & 0.0 \\
-20.3 & 2.5 & 1.6 \\
14.0 & 17.2 & 2.0
\end{tabular}

Source: Computed by the authors as described in text. 
Table 11. Distribution of Saving Rates in the PSID and HRS

\begin{tabular}{|c|c|c|c|c|}
\hline $\begin{array}{c}\text { Multiple } \\
\text { of Income }\end{array}$ & $\begin{array}{c}\text { Total } \\
\text { saving }\end{array}$ & $\begin{array}{c}\text { Equity- } \\
\text { type } \\
\text { Saving }\end{array}$ & $\begin{array}{c}\text { Housing } \\
\text { Saving }\end{array}$ & $\begin{array}{c}\text { Fixed- } \\
\text { price } \\
\text { Saving } \\
\end{array}$ \\
\hline & \multicolumn{4}{|c|}{ PSID: 1984-2005 (6 subperiods) } \\
\hline$<-1$ & 3.3 & 0.4 & 1.0 & 2.5 \\
\hline-1 to 0 & 28.5 & 4.5 & 12.4 & 31.0 \\
\hline zero & 18.3 & 80.1 & 51.9 & 29.0 \\
\hline 0 to +1 & 45.6 & 14.4 & 33.6 & 34.9 \\
\hline \multirow[t]{3}{*}{$>1$} & 4.3 & 0.6 & 1.0 & 2.7 \\
\hline & 100.1 & 100.0 & 100.0 & 100.0 \\
\hline & \multicolumn{4}{|c|}{ HRS: 1992-2004 (6 subperiods) } \\
\hline$<-1$ & 10.7 & 1.0 & 3.9 & 8.0 \\
\hline-1 to 0 & 27.1 & 4.6 & 13.0 & 32.4 \\
\hline zero & 9.6 & 79.5 & 43.6 & 14.8 \\
\hline 0 to +1 & 38.2 & 12.7 & 35.3 & 35.6 \\
\hline \multirow{2}{*}{$>1$} & 14.3 & 2.1 & 4.2 & 9.3 \\
\hline & 100.0 & 100.0 & 100.0 & 100.0 \\
\hline
\end{tabular}


Table 12. Regression Estimates of Active Saving from the PSID and HRS, 1984-2005

\begin{tabular}{|c|c|c|c|c|c|c|c|c|c|c|c|c|c|c|c|}
\hline & \multicolumn{10}{|c|}{ PSID } & \multicolumn{5}{|c|}{ HRS } \\
\hline & \multicolumn{5}{|c|}{ 1984-1999 } & \multicolumn{5}{|c|}{ 1999-2005 } & \multicolumn{5}{|c|}{ 1992-2004 } \\
\hline & (1) & (2) & (3) & (4) & (5) & (6) & (7) & $(8)$ & (9) & (10) & (11) & (12) & (13) & (14) & (15) \\
\hline Employer Pension & -13.9 & -14.0 & -10.3 & -10.7 & -11.7 & -2.4 & -2.2 & -1.5 & -1.8 & -1.7 & 6.8 & 5.8 & 6.5 & 5.3 & 6.3 \\
\hline & $(-3.6)$ & $(-3.6)$ & $(-3.1)$ & $(-2.9)$ & $(-3.1)$ & $(-1.6)$ & $(-1.5)$ & $(-1.2)$ & $(-1.3)$ & $(-1.2)$ & (4.1) & (3.5) & (4.1) & (3.2) & (3.8) \\
\hline Employer Pension x Income & 0.03 & 0.03 & 0.03 & 0.02 & 0.03 & & & & & & -0.14 & -0.12 & -0.14 & -0.1 & -0.14 \\
\hline & $(2.8)$ & (2.8) & (2.6) & (2.1) & $(2.2)$ & & & & & & $(-12.2)$ & $(-10.4)$ & $(-12.9)$ & $(-8.8)$ & $(-12.6)$ \\
\hline Initial Wealth & $\begin{array}{l}-0.1 \\
(-4.5)\end{array}$ & $\begin{array}{l}-0.11 \\
(-4.8)\end{array}$ & $\begin{array}{l}0.07 \\
(3.7)\end{array}$ & $\begin{array}{l}-0.09 \\
(-4.6)\end{array}$ & $\begin{array}{l}-0.07 \\
(-3.4)\end{array}$ & $\begin{array}{c}-0.25 \\
(-16.9)\end{array}$ & $\begin{array}{l}-0.23 \\
(-15.3)\end{array}$ & $\begin{array}{l}-0.08 \\
(-7.6)\end{array}$ & $\begin{array}{c}-0.17 \\
(-12.4)\end{array}$ & $\begin{array}{c}-0.25 \\
(-18.9)\end{array}$ & $\begin{array}{l}-0.03 \\
(-10.8)\end{array}$ & $\begin{array}{l}-0.03 \\
-10.1)\end{array}$ & $\begin{array}{l}-0.01 \\
(-4.3)\end{array}$ & $\begin{array}{l}-0.03 \\
(-12.3)\end{array}$ & $\begin{array}{l}-0.01 \\
(-5.1)\end{array}$ \\
\hline Marital Transition & & & & & & & & & & & & & & & \\
\hline$\overline{\text { Married }}$ & $\begin{array}{c}3.7 \\
(1.0)\end{array}$ & $\begin{array}{c}3.7 \\
(1.0)\end{array}$ & $\begin{array}{c}8.3 \\
(2.7)\end{array}$ & $\begin{array}{c}3.8 \\
(1.1)\end{array}$ & $\begin{array}{c}3.6 \\
(1.0)\end{array}$ & $\begin{array}{l}0.1 \\
0.0\end{array}$ & $\begin{array}{c}0.4 \\
(0.1)\end{array}$ & $\begin{array}{l}-0.6 \\
(-0.2)\end{array}$ & $\begin{array}{c}0.2 \\
(0.1)\end{array}$ & $\begin{array}{c}0.0 \\
(-0.0)\end{array}$ & $\begin{array}{l}-5.9 \\
(-1.1)\end{array}$ & $\begin{array}{l}-5.1 \\
(-1.0)\end{array}$ & $\begin{array}{c}-3.3 \\
(-0.6)\end{array}$ & $\begin{array}{l}-5.3 \\
(-1.0)\end{array}$ & $\begin{array}{c}-6.4 \\
(-1.2)\end{array}$ \\
\hline Divorced & $\begin{array}{l}-9.5 \\
(-2.3)\end{array}$ & $\begin{array}{c}-9.5 \\
(-2.3)\end{array}$ & $\begin{array}{l}-0.8 \\
(-0.2)\end{array}$ & $\begin{array}{l}-9.7 \\
(-2.4)\end{array}$ & $\begin{array}{l}-9.1 \\
(-2.3)\end{array}$ & $\begin{array}{l}-15.4 \\
(-3.7)\end{array}$ & $\begin{array}{l}-15.4 \\
(-3.8)\end{array}$ & $\begin{array}{c}-5.4 \\
(-1.5)\end{array}$ & $\begin{array}{l}-15.9 \\
(-3.8)\end{array}$ & $\begin{array}{l}-15.3 \\
(-3.7)\end{array}$ & $\begin{array}{l}-13.9 \\
(-1.9)\end{array}$ & $\begin{array}{l}-13.7 \\
(-1.9)\end{array}$ & $\begin{array}{l}0.7 \\
-0.1\end{array}$ & $\begin{array}{l}-10.8 \\
(-1.5)\end{array}$ & $\begin{array}{l}-10.6 \\
(-1.5)\end{array}$ \\
\hline Net Transfers & $\begin{array}{l}0.18 \\
(4.4)\end{array}$ & $\begin{array}{l}0.18 \\
(4.5)\end{array}$ & $\begin{array}{l}0.16 \\
(4.7)\end{array}$ & $\begin{array}{c}0.2 \\
(5.0)\end{array}$ & $\begin{array}{l}0.19 \\
(4.7)\end{array}$ & $\begin{array}{l}0.16 \\
(6.0)\end{array}$ & $\begin{array}{l}0.17 \\
(6.3)\end{array}$ & $\begin{array}{l}0.08 \\
(3.3)\end{array}$ & $\begin{array}{l}0.16 \\
(5.8)\end{array}$ & $\begin{array}{l}0.16 \\
(6.0)\end{array}$ & $\begin{array}{c}0.0 \\
(-0.2)\end{array}$ & $\begin{array}{c}0.0 \\
(-0.4)\end{array}$ & $\begin{array}{c}-0.1 \\
(-1.4)\end{array}$ & $\begin{array}{c}0.0 \\
(-0.4)\end{array}$ & $\begin{array}{c}0.0 \\
(-0.1)\end{array}$ \\
\hline Income & $\begin{array}{l}0.07 \\
(5.0)\end{array}$ & $\begin{array}{l}0.07 \\
(5.0)\end{array}$ & $\begin{array}{l}0.04 \\
(3.4)\end{array}$ & $\begin{array}{l}0.05 \\
(4.0)\end{array}$ & $\begin{array}{l}0.07 \\
(5.0)\end{array}$ & $\begin{array}{l}0.09 \\
(5.8)\end{array}$ & $\begin{array}{l}0.09 \\
(6.1)\end{array}$ & $\begin{array}{l}0.05 \\
(4.0)\end{array}$ & $\begin{array}{l}0.08 \\
(5.1)\end{array}$ & $\begin{array}{l}0.08 \\
(5.6)\end{array}$ & $\begin{array}{l}0.06 \\
(6.7)\end{array}$ & $\begin{array}{l}0.05 \\
(4.7)\end{array}$ & $\begin{array}{l}0.06 \\
(6.1)\end{array}$ & $\begin{array}{l}0.02 \\
(2.0)\end{array}$ & $\begin{array}{l}0.06 \\
(6.7)\end{array}$ \\
\hline Passive Saving & & & & & & & & & & & & & & & \\
\hline Total & $\begin{array}{l}-0.03 \\
(-2.1)\end{array}$ & & & & & $\begin{array}{l}-0.05 \\
(-4.8)\end{array}$ & & & & & $\begin{array}{l}-0.01 \\
(-5.9)\end{array}$ & & & & \\
\hline Home & & $\begin{array}{l}-0.07 \\
(-2.5)\end{array}$ & $\begin{array}{c}0.1 \\
(4.3)\end{array}$ & & & & $\begin{array}{l}-0.12 \\
(-6.0)\end{array}$ & $\begin{array}{l}0.00 \\
(-0.2)\end{array}$ & & & & $\begin{array}{l}-0.05 \\
(-6.3)\end{array}$ & $\begin{array}{l}0.02 \\
(3.1)\end{array}$ & & \\
\hline Equities & & $\begin{array}{l}-0.01 \\
(-0.4)\end{array}$ & & $\begin{array}{l}0.01 \\
(0.3)\end{array}$ & & & $\begin{array}{l}0.06 \\
(4.1)\end{array}$ & & $\begin{array}{l}0.08 \\
(5.8)\end{array}$ & & & $\begin{array}{l}-0.02 \\
(-7.3)\end{array}$ & & $\begin{array}{l}-0.01 \\
(-4.0)\end{array}$ & \\
\hline Business and Real Estate & & $\begin{array}{l}-0.03 \\
(-1.3)\end{array}$ & & & $\begin{array}{l}0.00 \\
(0.2)\end{array}$ & & $\begin{array}{l}-0.12 \\
(-7.9)\end{array}$ & & & $\begin{array}{l}-0.12 \\
(-7.8)\end{array}$ & & $\begin{array}{c}0 \\
(-0.0)\end{array}$ & & & $\begin{array}{l}0.02 \\
(5.8)\end{array}$ \\
\hline Constant & $\begin{array}{c}3.7 \\
(1.1)\end{array}$ & $\begin{array}{c}4.0 \\
(1.2)\end{array}$ & $\begin{array}{l}-4.1 \\
(-1.4)\end{array}$ & $\begin{array}{c}4.9 \\
(1.5)\end{array}$ & $\begin{array}{c}1.4 \\
(0.4)\end{array}$ & $\begin{array}{c}6.4 \\
(2.5)\end{array}$ & $\begin{array}{l}5.3 \\
(2.1)\end{array}$ & $\begin{array}{c}2.0 \\
(0.9)\end{array}$ & $\begin{array}{c}4.2 \\
(1.6)\end{array}$ & $\begin{array}{l}6.4 \\
(2.5)\end{array}$ & $\begin{array}{l}10.1 \\
(4.5)\end{array}$ & $\begin{array}{l}11.6 \\
(5.1)\end{array}$ & $\begin{array}{l}-1.9 \\
(-0.9)\end{array}$ & $\begin{array}{l}11.5 \\
(5.2)\end{array}$ & $\begin{array}{c}5.8 \\
(2.6)\end{array}$ \\
\hline R2 & 0.04 & 0.04 & 0.03 & 0.03 & 0.03 & 0.05 & 0.06 & 0.01 & 0.05 & 0.05 & 0.02 & 0.03 & 0.02 & 0.03 & 0.02 \\
\hline Observations & 4,920 & 4,920 & 4,920 & 4,920 & 4,920 & 11,364 & 11,364 & 11,364 & 11,364 & 11,364 & 16,411 & 16,411 & 16,411 & 16,411 & 16,411 \\
\hline Families & 1,640 & 1,640 & 1,640 & 1,640 & 1,640 & 3,788 & 3,788 & 3,788 & 3,788 & 3,788 & 5,470 & 5,470 & 5,470 & 5,470 & 5,470 \\
\hline
\end{tabular}

Notes: Categorical variables for age, homeownership, and stock holders at the beginning of each sub-period were included in the regression but not reported in the table. Beginning of period wealth excludes fixed-income assets. Employer pension is a dummy 
Figure 1. Comparison of Net Worth between the Survey of Consumer Finances and Flow of Funds Estimates, 1983-2004

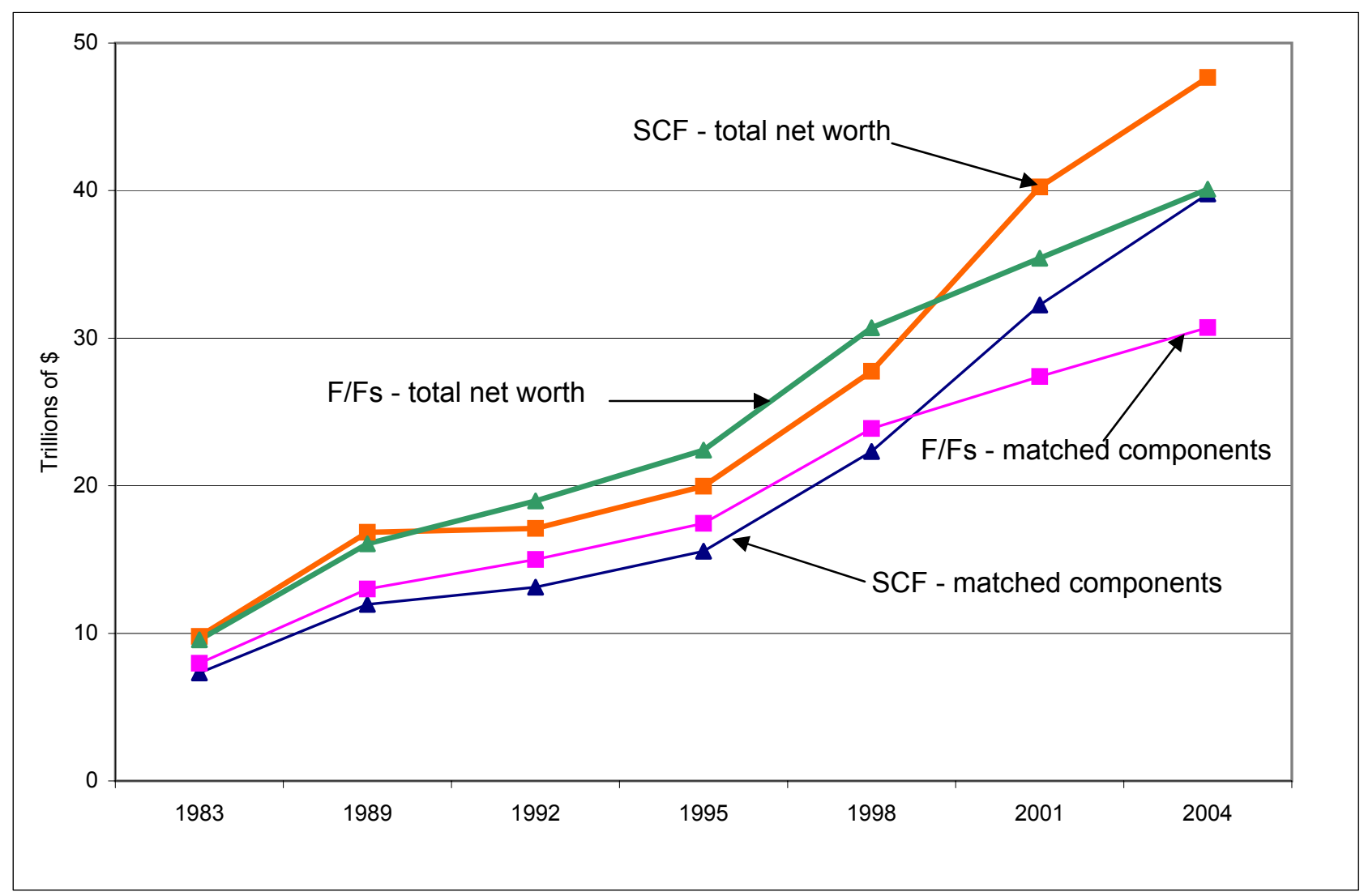

Sources: 1983-2004 SCF, Flow of Funds Accounts, Antoniewicz (2000), and authors' estimates.

Notes: All FFA estimates are two-year averages of end-of-year data and exclude consumer durables and the assets and liabilities of nonprofit institutions. Net worth for the SCF is calculated as the difference between total assets and liabilities, consistent with the definitions used on the the SCF web site with the exception of the exclusion of motor vehicles. Note that SCF liabilities in the matching components exceed total liabilities because the SCF definition nets nonresidential real estate debt against non-residential assets. 
Figure 2. Mean Household Wealth by Uniform SCF Decile, 1983-2005

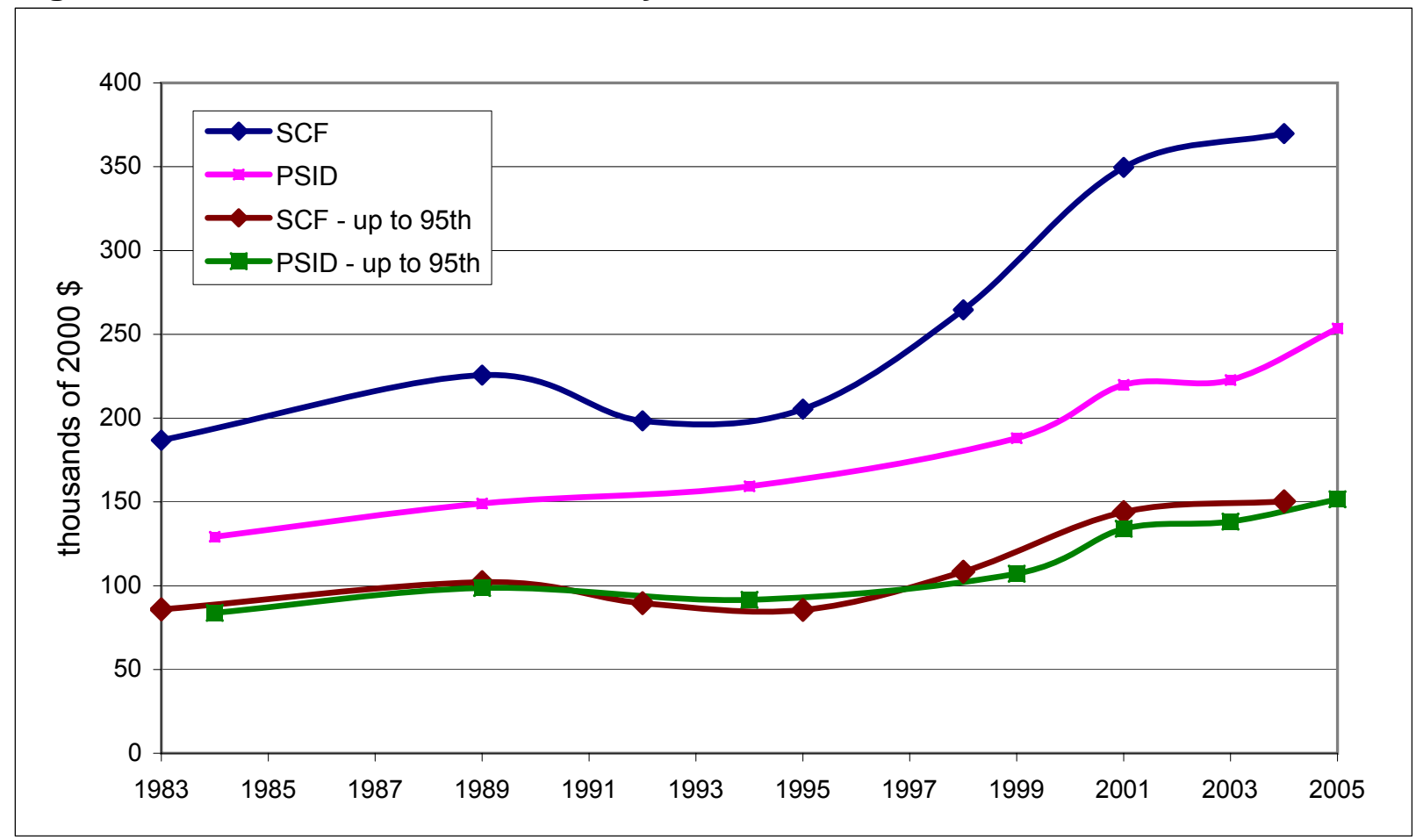

Sources: 1984-2005 PSID and 1983-2004 SCF public-use files, and authors' estimates.

Notes: Results are shown for the entire wealth distribution as well as for only those households whose wealth holdings fall below the 95th wealth percentile. The uniform percentile breakpoints in the wealth distribution are calculated from the nearest SCF years using the entire population. 
Figure 3. Mean Household Wealth by Age and Educational Attainment of the Household Head for the Survey of Consumer Finances and Panel Study of Income Dynamics, 1983-2005

Panel A: SCF Age-Wealth Profiles

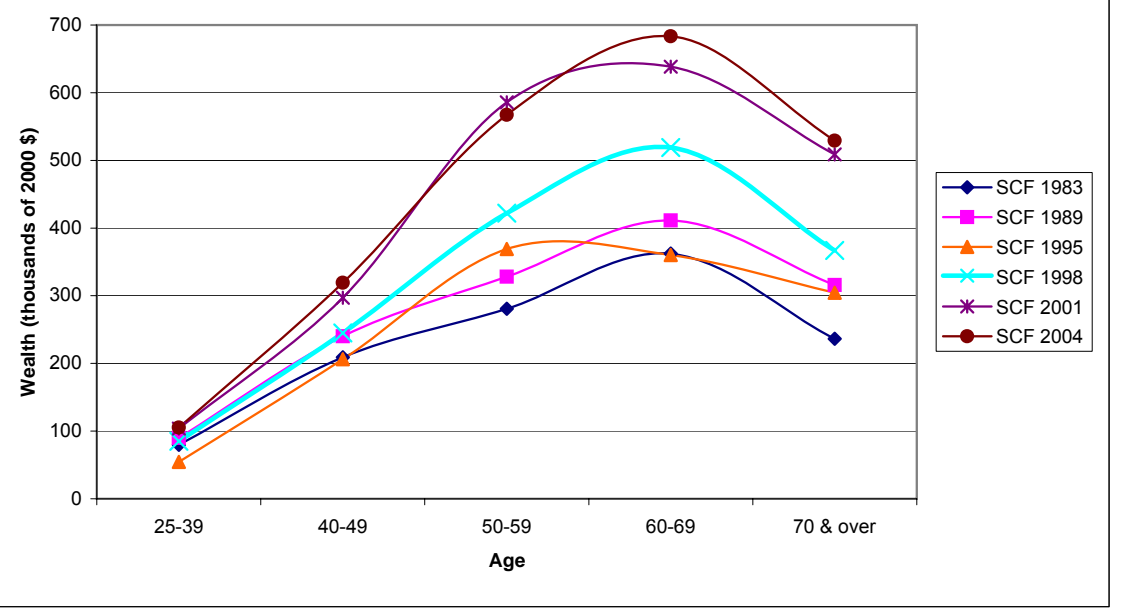

Panel C: SCF Education and Wealth

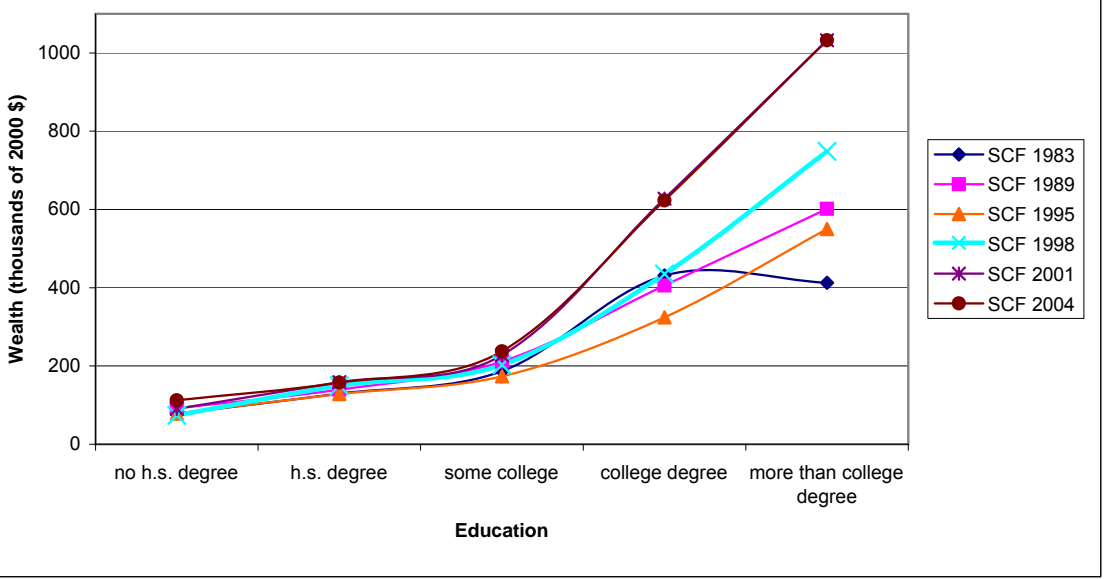

Panel B: PSID Age-Wealth Profile

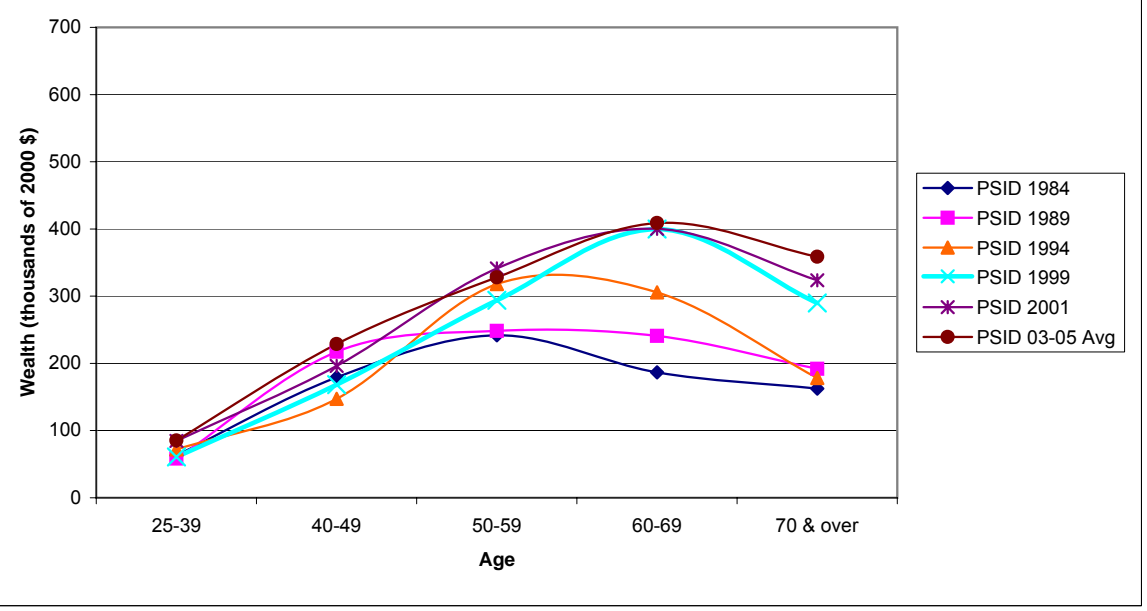

Panel D: PSID Education and Wealth

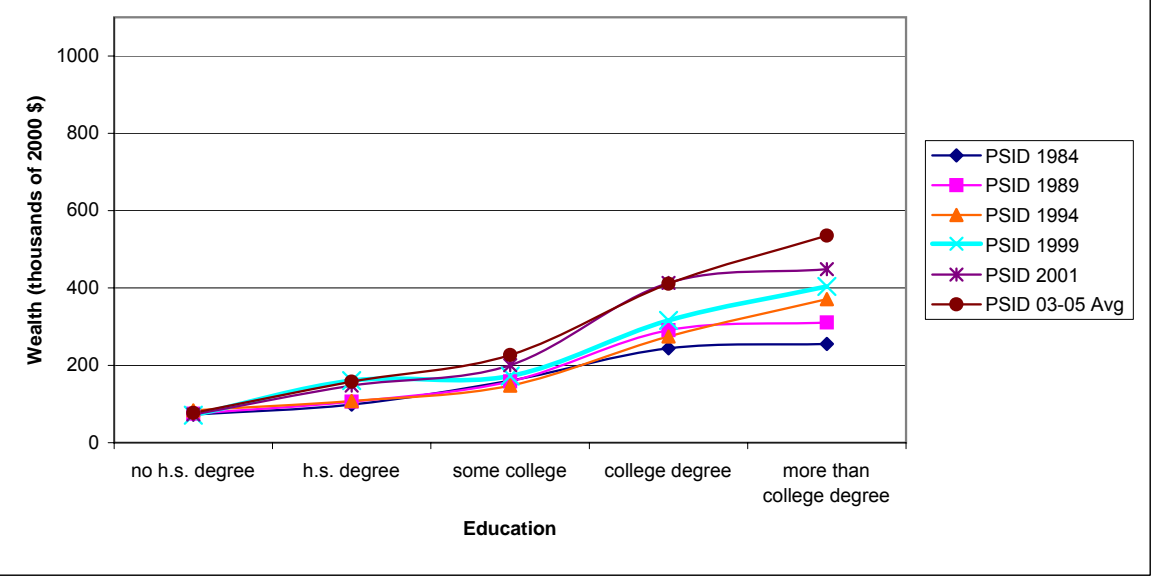

Sources: 1984-2005 PSID and 1983-2004 SCF public-use files, and authors' estimates.

Notes: The mean wealth from the PSID 2003 and 2005 surveys are averaged for more accurate comparison with the calculated mean wealth for the 2004 SCF. 
Figure 4. Mean Wealth by Wealth Category for the Surveys of Consumer Finances and the Panel Study of Income Dynamics, 1983-2005
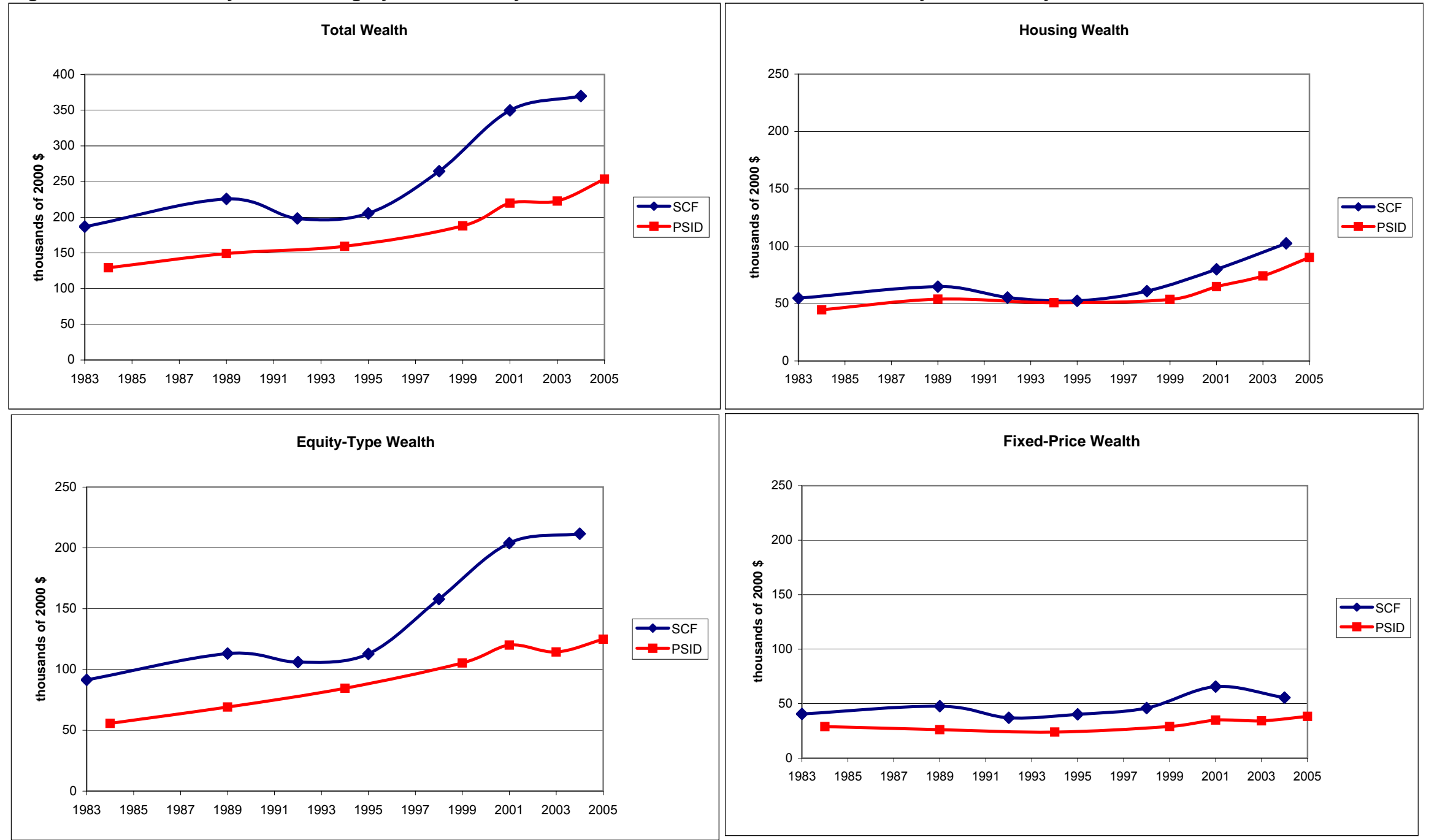

Sources: 1984-2005 PSID and 1983-2004 SCF public-use files, and authors' estimates. Notes: The specific components of the given wealth categories are given in the appendix. 
Figure 5. Mean Wealth by Uniform SCF Decile, 1992-2005

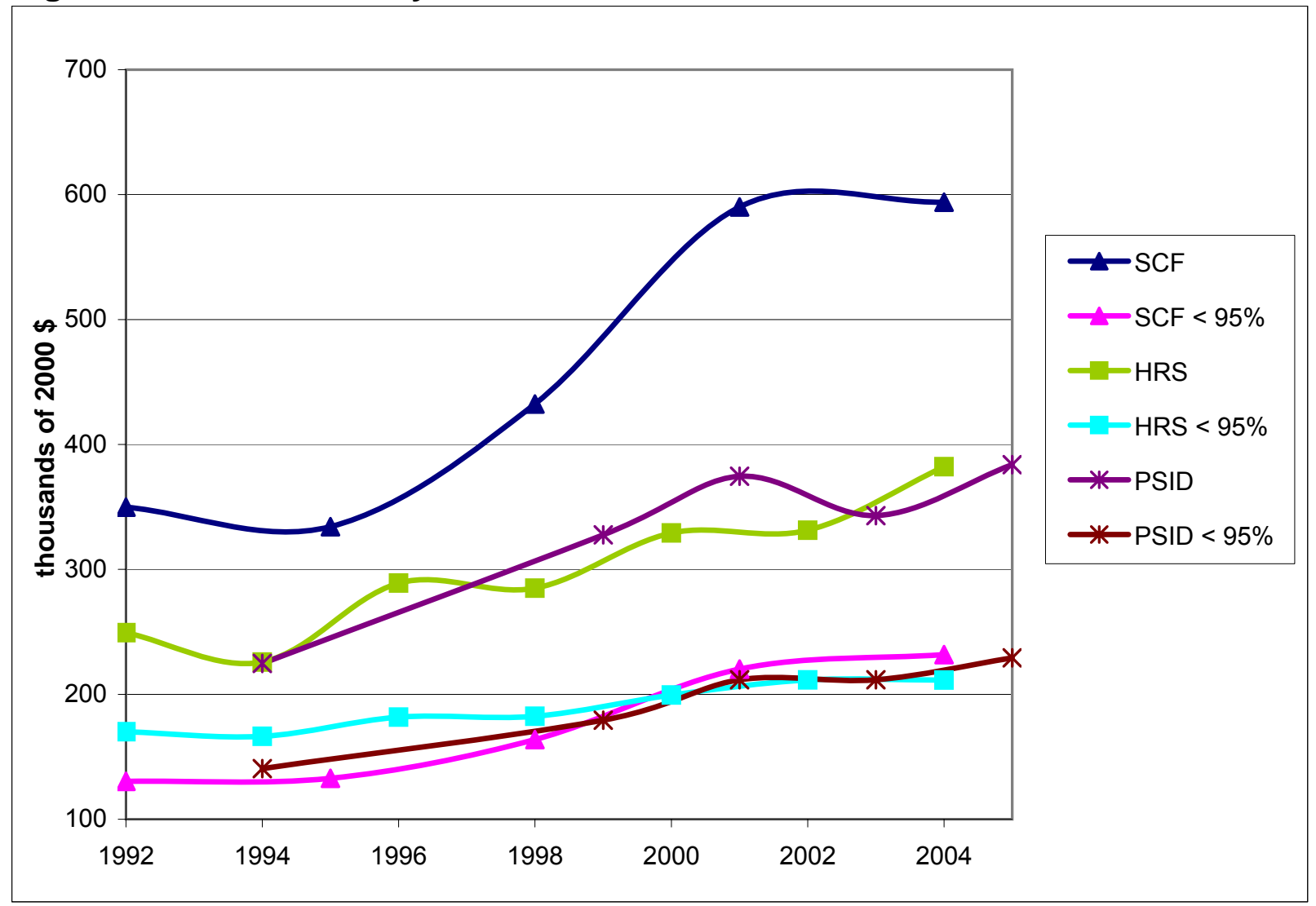

Sources: PSID, HRS, and SCF public-use files for selected years, and authors' estimates.

Notes: Results are presented for each survey separately. Mean wealth is given for different cohorts of the population according to which cohorts were incorporated into the HRS survey during that year.

Results are shown for the entire wealth distribution as well as for only those households whose wealth holdings fall below the 95th wealth percentile. The uniform percentile breakpoints in the wealth distribution are calculated from the nearest SCF years using the entire population. 
Figure 6. Mean Wealth by Birth Cohort of Household Head for the Health and Retirement Surveys, Surveys of Consumer Finances and Panel Study of Income Dynamics, 1992-2004
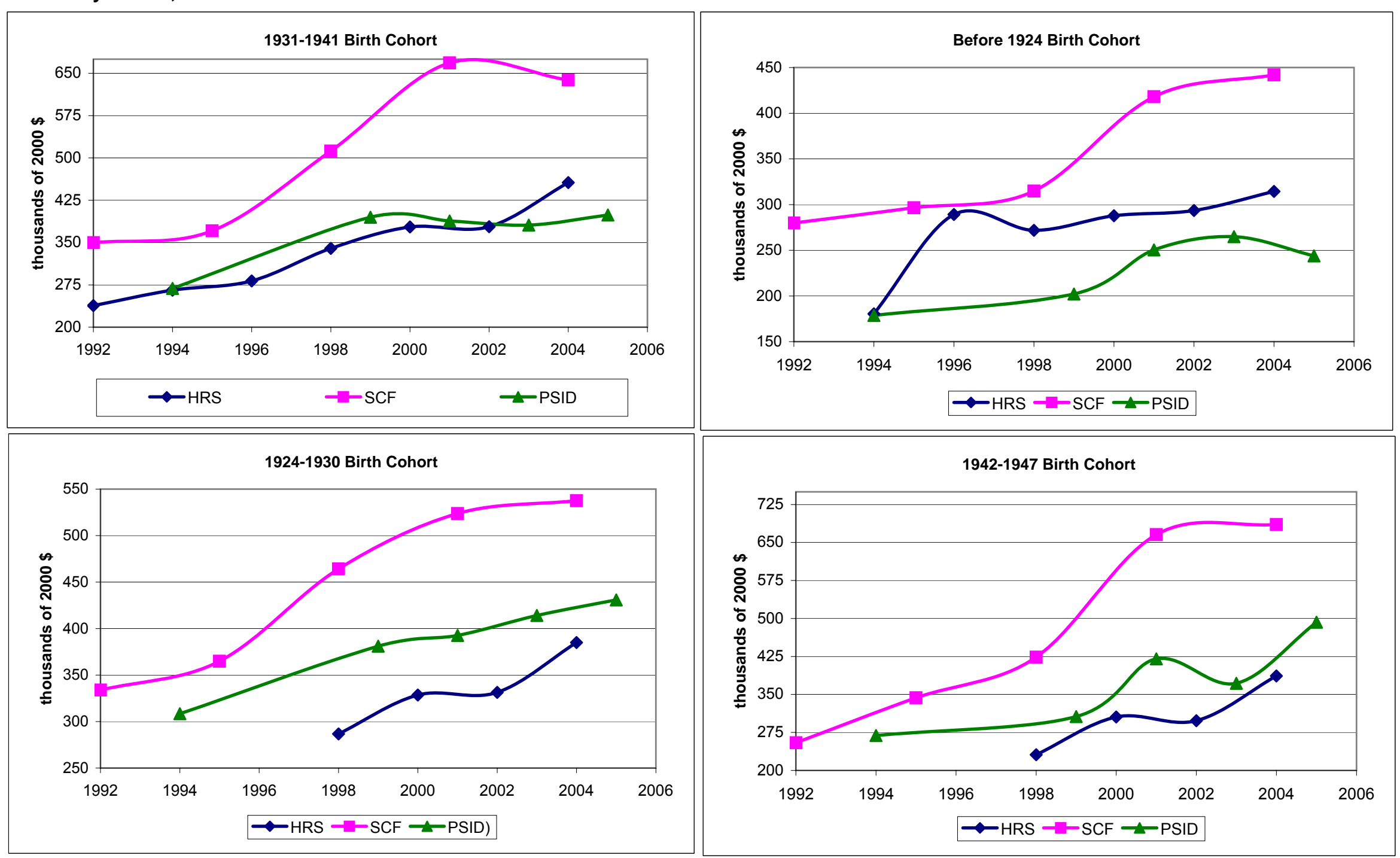

Sources: PSID, HRS, and SCF public-use files for selected years, and authors' estimates.

Notes: Mean wealth is given for different cohorts of the population according to when each cohort was incorporated into the HRS survey. 
Figure 7. Mean Household Wealth by Educational Attainment of Household Head for the 1931-1941 Birth Cohort in the HRS, 1992-2004

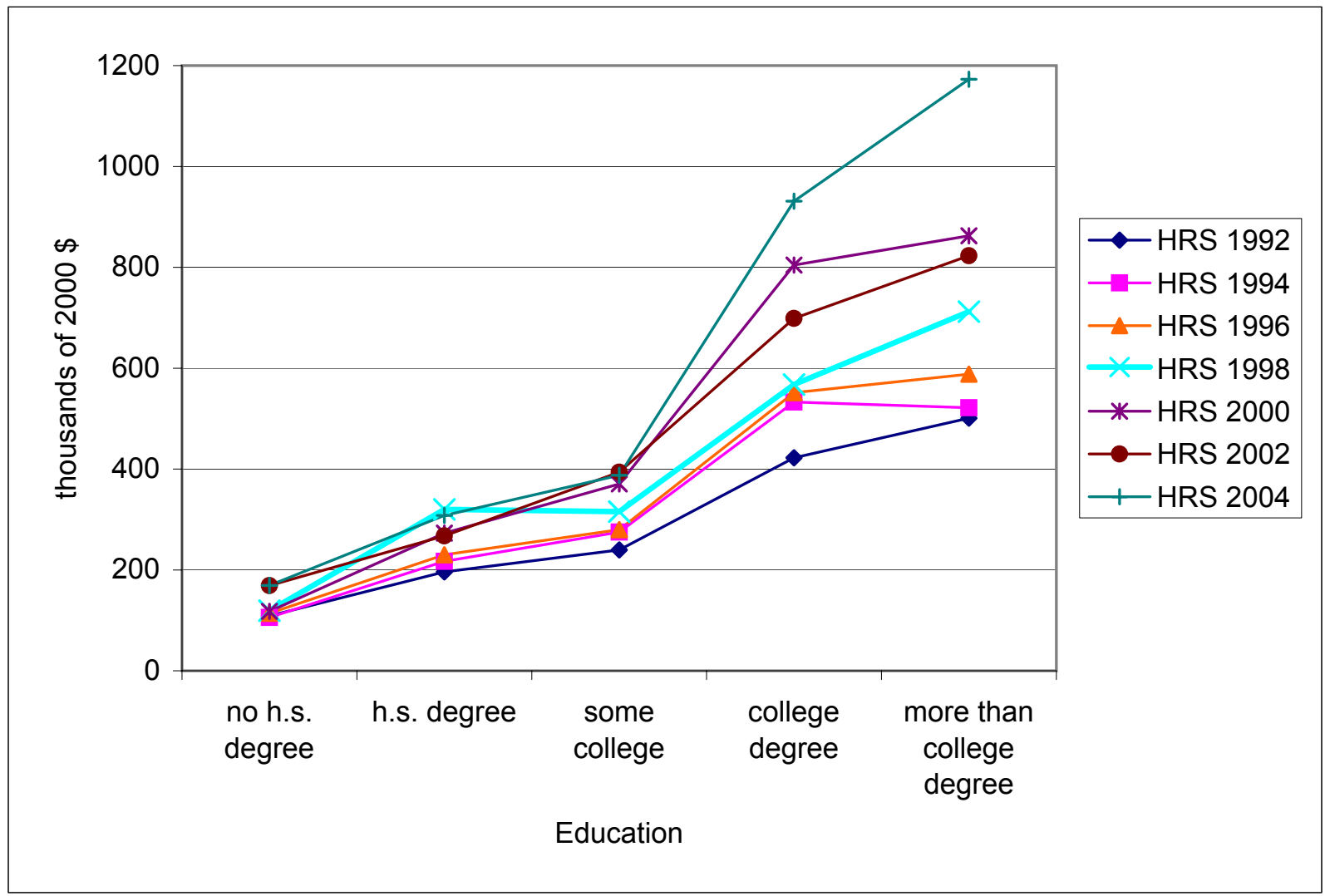

Sources: 1992-2004 Health and Retirement Surveys, and authors' estimates.

Notes: Mean wealth is shown only for surveyed households where the head of household was born between 1931 and 1941 (part of the HRS cohort). 
Figure 8. Mean Wealth of Individuals by Status in HRS Survey, 1992 Participants

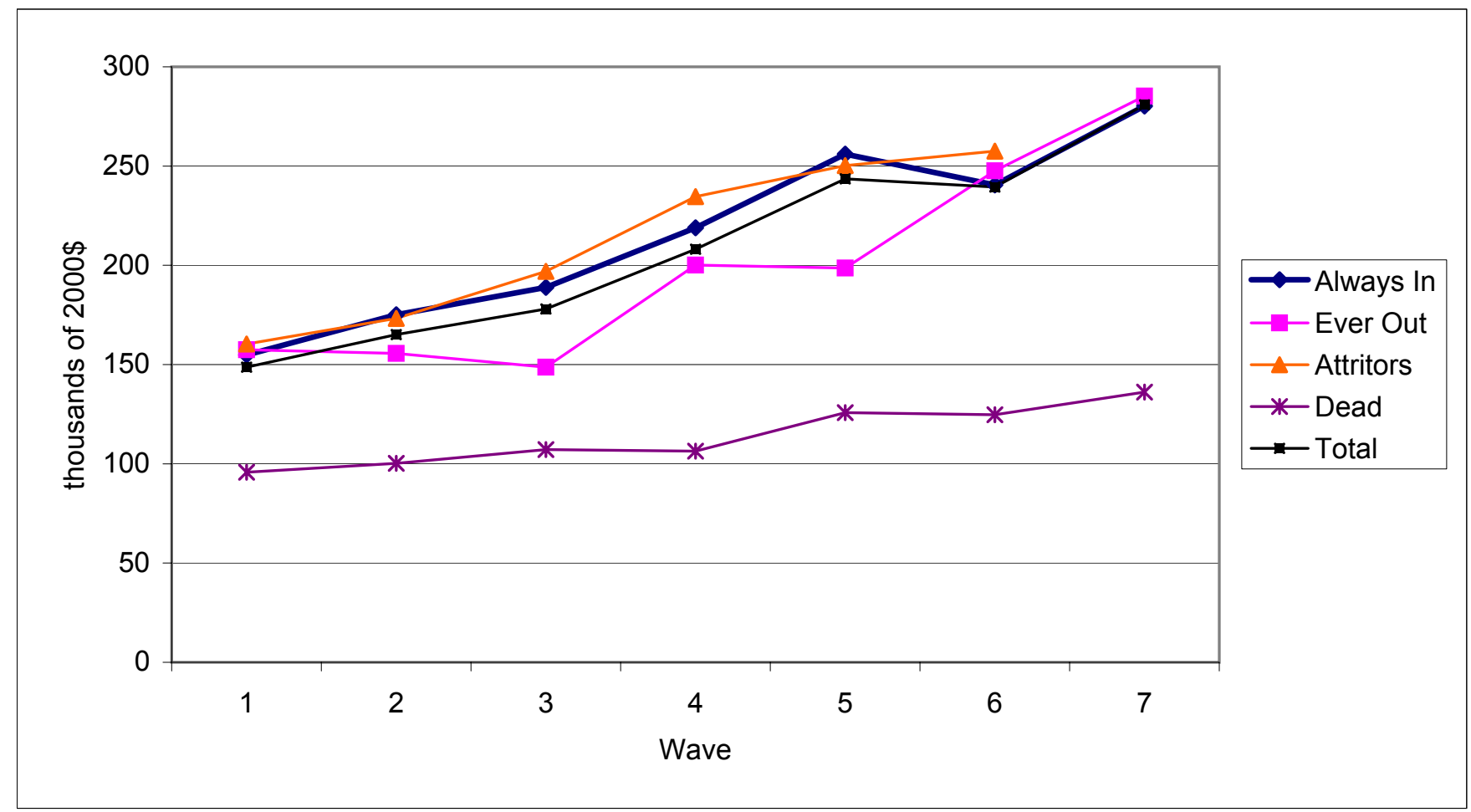

Source: Computed by the authors for the 1931-41 birth cohort. Attritors exclude those who become non-response due to death. Ever Out are persons who missed one or more wave, but were present in 2004. Data are from the 2006 HRS tracking file.

Note: The allocation of the 9,779 individuals present in 1992 is: always in $(60 \%)$, ever out $(9 \%)$, attritors $(13 \%)$, and died (18\%) 
Figure 9. Annual Probability of Death by Age and Selected Wealth Percentiles in the Health and Retirement Surveys, 1992-2004
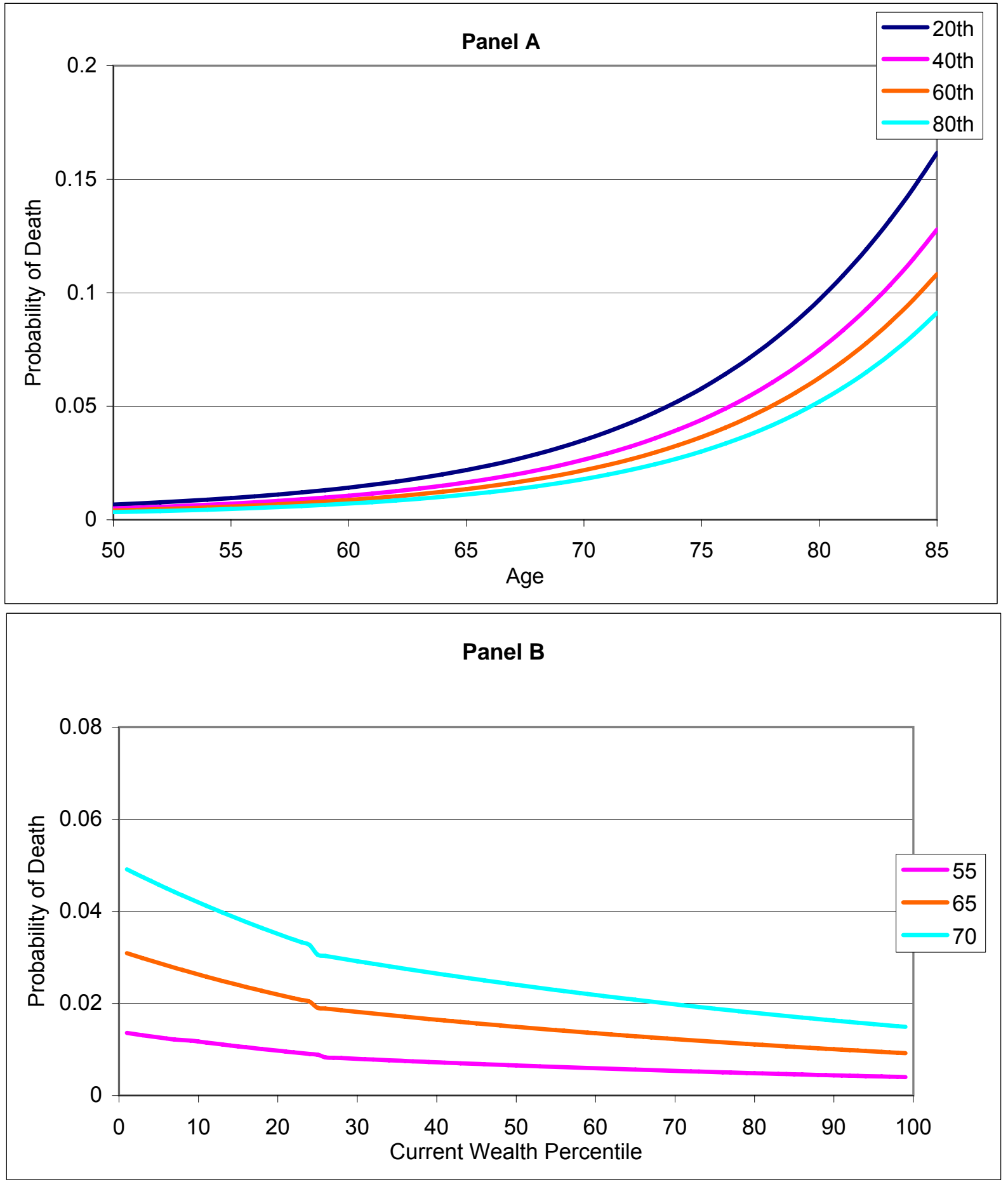

Sources:1992-2004 Health and Retirement Surveys, 2006 HRS Tracker File, and authors' estimates.

Notes: Annual probability of death is calculated using esimates from Regression (1) of Table 5. The tabulations are based on individuals, with the wealth of couple households split equally between the head and spouse. Wealth percentile is calculated separately for each age group and survey year. 
Figure 10. Age- Wealth Profile of the Health and Retirement Survey of 2004, Corrected for Mortality

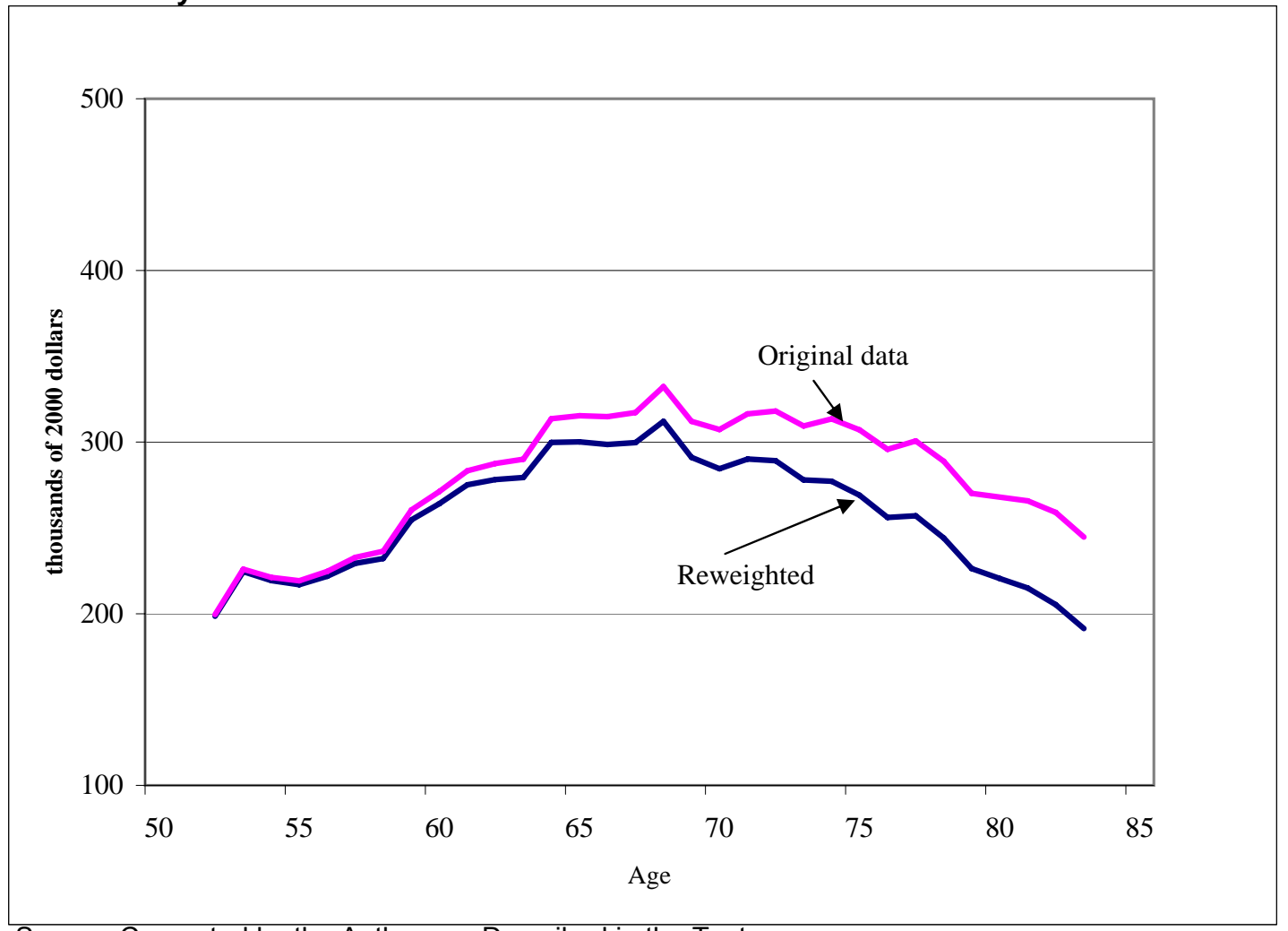

Source: Computed by the Authors as Described in the Text. 
Figure 11. Mean and Median Wealth of Individuals by Status in PSID Survey

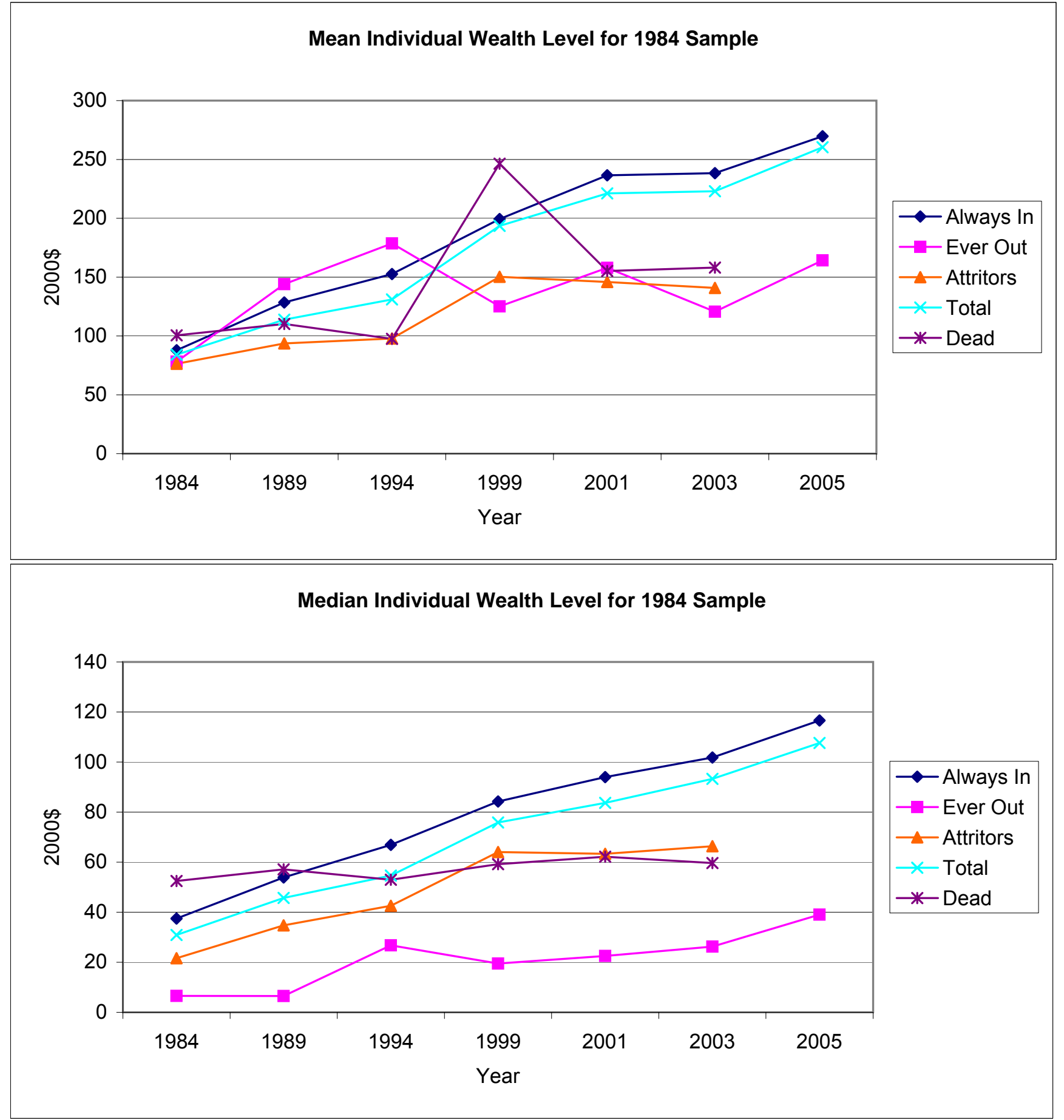

Source: Computed by the authors for all individuals in the 1984 wave. Attritors exclude those who are dead. Ever Out are persons who missed one or more wave, but were present in 2005. excludes persons who missed a prior wave and returned, but were not present in 2005.

Note: The allocation of the 10,674 individuals present in 1984 is: always in $(31 \%)$, ever out $(5 \%)$, attritors $(51 \%)$, and died (13\%). 


\section{Appendix A: Data Sources}

The basic data are all downloaded from the web sites of the PSID and the HRS, but we have made some modifications to both data sets. The modifications are described below.

\section{PSID}

The wealth data are available from supplemental modules in seven years (1984, 1989, 1994, 1999, 2001, 2003, and 2005); and the non-housing components were already imputed for missing values. The responses to the active saving questions are available for 1989 to 2005, and imputations were included for 1984-89 and 1989-94. We extended the data set in three respects. First, the wealth files included only net home equity, whereas the value of the home and the mortgage are available annually - biennially after 1997.

Imputed values of the home and mortgage components are not included for the years after 1993. We extended those imputations. Second, we altered the imputation process for open-ended brackets as explained below. Third, we extended the imputation of the active saving measures for the periods beyond 1994.

For housing, information on home value, mortgage debt, and whether or not the household moved is available for every survey - annually prior to 1997. To impute missing home and mortgage values we followed the same procedures used more generally in the official releases. We also altered data in a few cases where respondents said they had not moved but the ownership status changed from owning to renting and back to owning.

The imputation procedure used in the PSID assigns values to the missing cases from a matching sub file of all individuals for whom the question applied. The method can produce unrealistic values for some small open-ended classes in that it may impute the same value to a string of households, and in open-ended classes that value could potentially be quite extreme. In the case of some uncommon asset categories, the sample size could be less than ten households. We altered the procedure for open-ended classes to assign to all missing values the median of those reporting a value within the class.

\section{HRS}

We have used data from the seven biennial surveys covering 1992-2004. The basic data are largely drawn from the RAND HRS Data file, which is a cleaned version of the original HRS files. It includes a significant number of computed variables and series are consistently named across the various waves. However, the answers to the active saving questions are not included in the RAND file, and we obtained them from the core HRS files. All if the data series included imputed values.

The HRS screens housing units for household members that fall within specific birth cohorts. The household member along with any spouse or partner represents a unit. Elderly persons living with their children and who are financially interdependent are still counted as their own household along with their spouse or partner. In addition, income and wealth data are not collected for other family members. 
We have tried to align the data with the definition of the household head that is used in the PSID. If the household has both a male and a female member, the male is designated as the household head. If the couple is of the same sex, then the elder of the two is designated as the household head. The designation is done in each wave to ensure that cross-wave comparisons are limited to households with an unchanged head - as a measure of a stable household composition. While the HRS includes institutionalized respondents, the household weights are structured to match the CPS, which includes living, non-institutionalized respondents. Thus, a household in which the respondents are institutionalized at the time of the interview will have zero weights for that wave. The estimated number of aged household heads consistently exceeds those form the other surveys, but, if the sample is restricted to households without children, the numbers are very similar.

\section{Outliers}

For both the HRS and the PSID, we encountered a significant number of cases in which the recorded values for the wealth or active saving variables appear highly implausible. Measurement errors in the wealth variables can have a particularly pronounced effect on the estimates of the change in wealth or saving for which it dramatically increases the noise to signal ratio. The data sets from recent waves of the PSID have not been edited to identify anomalous values of for the responses to the wealth and saving questions.

We created algorithms to identify particularly egregious values. Our method takes advantage of the panel dimension of the data, but requires information from at least three successive waves of the surveys. We focused on the ratio of the value of each wealth component to an average of the values for the preceding and following period. We excluded cases with imputed values and required the values for the preceding and following periods to be within 25 percent of each other. The initial criteria for identifying an outlier required that the absolute value of the difference between the period value and the average of the surrounding years exceed 75 percent. However, the selection of values for examination also imposed other restrictions that incorporated possible explanations for large changes or evidence that the change was reflected in offsetting changes in other wealth components. If a value was judged to be extreme, it was replaced by the average of the prior and preceding periods. In most of those cases the value exceed the surrounding average by a factor of 10 or more, implying a problem with entering the data with the correct decimal location.

Although we could indentify some outliers for the active saving variables, we did not have a credible basis for providing alternative values. Thus, the active saving variables were flagged only for the purpose of observing the sensitivity of various results to their exclusion from the data set. The number of replacements for the HRS and the PSID are shown in the tables below. 
HRS

Number of Corrected Outliers

\begin{tabular}{rcccccccc} 
& Wave 1 & Wave & Wave & Wave 4 & Wave 5 & Wave 6 & Wave 7 \\
& 1992 & 1994 & 1996 & 1998 & 2000 & 2002 & 2004 \\
\cline { 2 - 8 } First House & - & 14 & 17 & 14 & 12 & 14 & - \\
Second House & - & 1 & 0 & 0 & 8 & 4 & - \\
First Mortgage & - & 24 & 29 & 31 & 24 & 47 & - \\
Second Mortgage & - & 0 & 0 & 3 & 3 & 1 & - \\
Value of Business & - & 5 & 10 & 17 & 10 & 9 & - \\
Value of Other Real Estate & - & 27 & 21 & 31 & 23 & 21 & - \\
Value of Stocks & - & 6 & 11 & 23 & 23 & 20 & - \\
Value of Checking & - & 4 & 2 & 3 & 1 & 5 & - \\
Value of Other Assets & - & 0 & 1 & 3 & 0 & 1 & - \\
Value of Debts & - & 2 & 2 & 1 & 1 & 2 & -
\end{tabular}

\section{Number of Flagged Observations}

Active Saving in Business

Active Saving in Other Real

Estate

Active Saving in Stocks

Active Saving in Housing

(movers)

-
-
-
-

19

$14-22$

$62 \quad 62$

22

15

9

9

34

28

39

46

42

$42 \quad 30$

29

25

25

37

26

30

PSID

Number of Corrected Outliers :

$\begin{array}{rccccccc}\text { Housing } & \underline{1984} & \underline{1989} & \underline{1994} & \underline{1999} & \underline{2001} & \underline{2003} & \underline{2005} \\ \text { Mortgage } & - & 12 & 45 & 21 & 22 & 28 & - \\ \text { Real Estate } & - & 7 & 4 & 10 & 19 & 12 & - \\ \text { Business } & - & 6 & 6 & 14 & 12 & 7 & - \\ \text { Stocks } & - & 1 & 2 & 15 & 25 & 18 & - \\ \text { Checking } & - & 7 & 7 & 5 & 3 & 3 & - \\ \text { Other } & - & 0 & 1 & 2 & 0 & 2 & - \\ \text { Debt } & - & 2 & 2 & 2 & 6 & 4 & - \\ \text { IRA } & - & - & - & 0 & 2 & 1 & - \\ \text { Total Changed: } & 0 & 38 & 93 & 74 & 96 & 83 & 0\end{array}$




\section{Table A1. Comparison of Survey of Consumer Finance Asset and Liability Categories with Flow of Funds Estimates, 1983-2004}

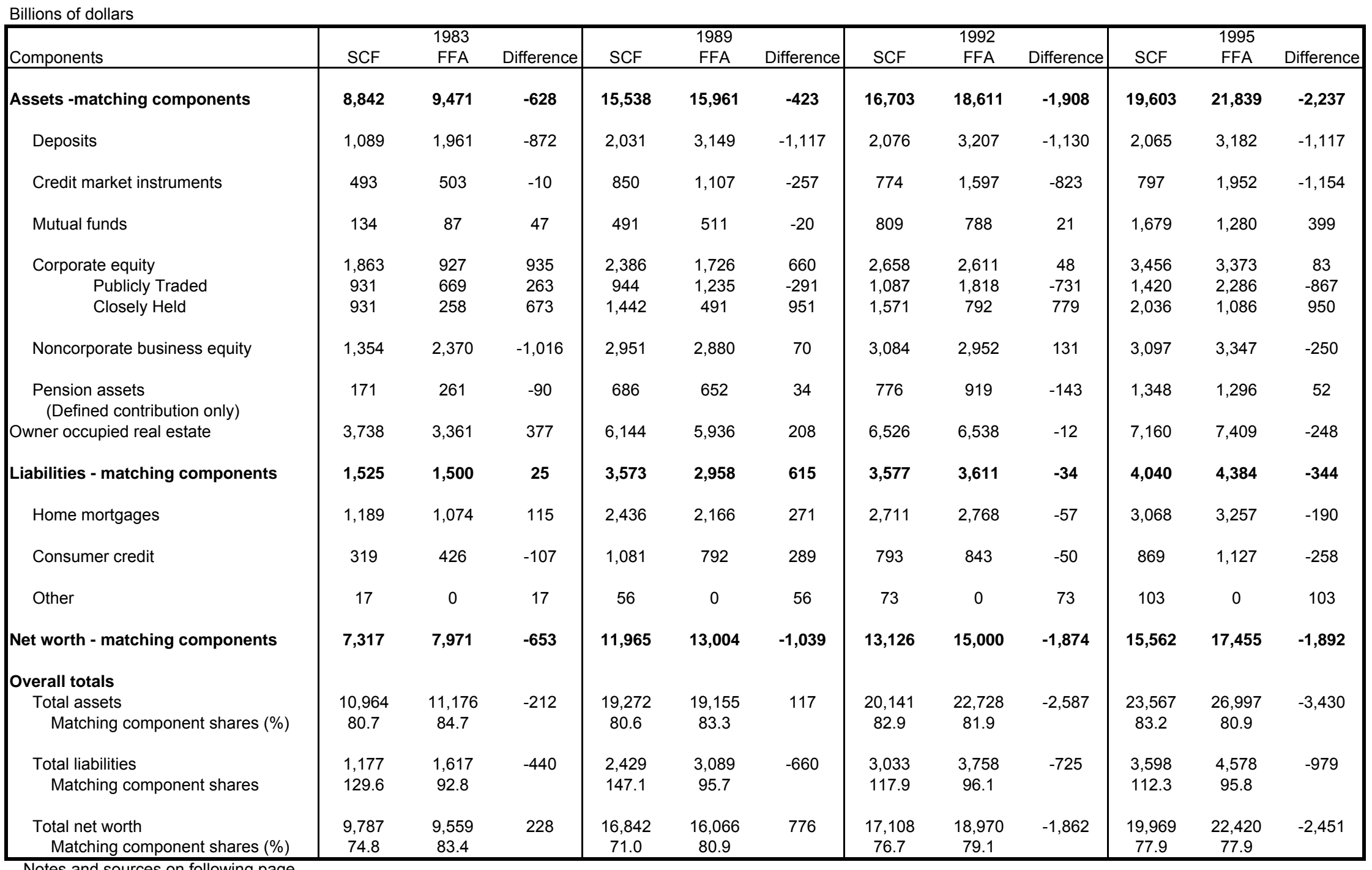

Notes and sources on following page. 
Table A1. Comparison of SCF Asset and Liability Categories with Flow of Funds Estimates, 1983-2004 (cont)

\begin{tabular}{|c|c|c|c|c|c|c|c|c|c|}
\hline \multirow[b]{2}{*}{ Components } & \multicolumn{3}{|c|}{1998} & \multicolumn{3}{|c|}{2001} & \multicolumn{3}{|c|}{2004} \\
\hline & SCF & FFA & Difference & SCF & FFA & Difference & SCF & FFA & Difference \\
\hline Assets -matching components & 27,449 & 29,210 & $-1,761$ & 38,357 & 34,326 & 4,031 & 49,256 & 40,258 & 8,997 \\
\hline Deposits & 2,727 & 3,654 & -927 & 3,740 & 4,475 & -735 & 4,484 & 5,408 & -924 \\
\hline Credit market instruments & 785 & 2,114 & $-1,329$ & 1,158 & 2,144 & -986 & 1,343 & 2,697 & $-1,354$ \\
\hline Mutual funds & 2,897 & 2,261 & 636 & 4,334 & 2,762 & 1,572 & 5,124 & 3,329 & 1,794 \\
\hline Corporate equity & 6,118 & 6,415 & -298 & 8,314 & 6,542 & 1,772 & 8,512 & 5,112 & 3,400 \\
\hline Publicly Traded & 3,130 & 4,930 & $-1,800$ & 4,360 & 4,905 & -546 & 3,701 & 3,810 & -109 \\
\hline Closely Held & 2,987 & 1,485 & 1,502 & 3,954 & 1,636 & 2,318 & 4,811 & 1,302 & 3,509 \\
\hline Noncorporate business equity & 3,995 & 3,931 & 65 & 5,433 & 4,611 & $\begin{array}{c}822 \\
0\end{array}$ & 7,625 & 5,542 & $\begin{array}{c}2,083 \\
0\end{array}$ \\
\hline $\begin{array}{l}\text { Pension assets } \\
\text { (Defined contribution only) }\end{array}$ & 1,716 & 2,093 & -377 & 2,612 & 2,363 & 248 & 3,373 & 2,646 & 726 \\
\hline Owner occupied real estate & 9,210 & 8,741 & 469 & 12,766 & 11,429 & 1,337 & 18,795 & 15,524 & 3,271 \\
\hline Liabilities - matching components & 5,122 & 5,328 & -207 & 6,111 & 6,929 & -818 & 9,476 & 9,538 & -62 \\
\hline Home mortgages & 3,901 & 3,907 & -6 & 4,750 & 5,074 & -324 & 7,606 & 7,366 & 239 \\
\hline Consumer credit & 1,042 & 1,422 & -380 & 1,225 & 1,855 & -630 & 1,728 & 2,172 & -445 \\
\hline Other & 180 & 0 & 180 & 136 & 0 & 136 & 143 & 0 & 143 \\
\hline Net worth - matching components & 22,327 & 23,881 & $-1,555$ & 32,246 & 27,396 & 4,850 & 39,780 & 30,720 & 9,059 \\
\hline Overall totals & & & & & & & & & \\
\hline $\begin{array}{l}\text { Total assets } \\
\text { Matching component shares (\%) }\end{array}$ & $\begin{array}{c}32,572 \\
84.3\end{array}$ & $\begin{array}{c}36,318 \\
80.4\end{array}$ & $-3,746$ & $\begin{array}{l}46,053 \\
83.3\end{array}$ & $\begin{array}{c}42,693 \\
80.4\end{array}$ & 3,359 & $\begin{array}{c}56,536 \\
87.1\end{array}$ & $\begin{array}{c}49,955 \\
80.6\end{array}$ & 6,581 \\
\hline Total liabilities & 4,817 & 5,616 & -799 & 5,806 & 7,272 & $-1,466$ & 8,866 & 9,863 & -997 \\
\hline Matching component shares (\%) & 106.3 & 94.9 & & 105.3 & 95.3 & & 106.9 & 96.7 & \\
\hline $\begin{array}{l}\text { Total net worth } \\
\text { Matching component shares (\%) }\end{array}$ & $\begin{array}{c}27,754 \\
80.4\end{array}$ & $\begin{array}{c}30,702 \\
77.8\end{array}$ & $-2,947$ & $\begin{array}{c}40,247 \\
80.1\end{array}$ & $\begin{array}{c}35,421 \\
77.3\end{array}$ & 4,826 & $\begin{array}{c}47,670 \\
83.4\end{array}$ & $\begin{array}{c}40,091 \\
76.6\end{array}$ & 7,578 \\
\hline
\end{tabular}

Sources: 1983-2004 Surveys of Consumer Finances, Flow of Funds Accounts, Antoniewicz (2000), and authors' estimates.

Notes: All FFA estimates are two-year averages of end-of-year data and exclude consumer durables and the assets and liabilities of nonprofit institutions. Total assets and liabilities of the SCF are consistent with the definitions used on the the SCF web site with the exception of the exclusion of motor vehicles. Note that SCF liabilities in the matching components exceed total liabilities because the SCF definition nets nonresidential real estate debt against non-residential assets. 
Table 2. Comparison of Mean Household Wealth and Income in the SCF and PSID by Age and Educational Attainment of the Household Head, 1983/84 to 2004/05

\begin{tabular}{|c|c|c|c|c|c|}
\hline SCFIPSID & $1983 / 1984$ & 1989 & 2001 & $2004 / 2005$ & Average \\
\hline \multicolumn{6}{|l|}{ Mean Wealth } \\
\hline All households & 1.45 & 1.51 & 1.59 & 1.55 & 1.53 \\
\hline \multicolumn{6}{|l|}{ Age of Head } \\
\hline $25-39$ & 1.26 & 1.54 & 1.23 & 1.23 & 1.32 \\
\hline $40-49$ & 1.16 & 1.10 & 1.51 & 1.39 & 1.29 \\
\hline $50-59$ & 1.16 & 1.32 & 1.72 & 1.73 & 1.48 \\
\hline $60-69$ & 1.94 & 1.71 & 1.59 & 1.67 & 1.73 \\
\hline 70 \& over & 1.46 & 1.65 & 1.57 & 1.48 & 1.54 \\
\hline \multicolumn{6}{|l|}{ Education of head } \\
\hline no h.s. degree & 1.07 & 1.23 & 1.24 & 1.46 & 1.25 \\
\hline h.s. degree & 1.31 & 1.32 & 1.07 & 1.00 & 1.17 \\
\hline some college & 1.16 & 1.34 & 1.14 & 1.05 & 1.17 \\
\hline college degree & 1.77 & 1.40 & 1.52 & 1.52 & 1.55 \\
\hline more than college degree & 1.62 & 1.93 & 2.30 & 1.93 & 1.95 \\
\hline \multicolumn{6}{|l|}{ Mean Income } \\
\hline All households & 1.03 & 1.13 & 1.07 & 1.12 & 1.09 \\
\hline \multicolumn{6}{|l|}{ Age of Head } \\
\hline $25-39$ & 0.99 & 1.06 & 1.00 & 0.96 & 1.00 \\
\hline $40-49$ & 0.94 & 1.11 & 1.07 & 1.10 & 1.05 \\
\hline $50-59$ & 0.95 & 1.07 & 1.26 & 1.20 & 1.12 \\
\hline $60-69$ & 1.22 & 1.09 & 1.11 & 1.25 & 1.17 \\
\hline 70 \& over & 1.11 & 1.46 & 0.98 & 1.28 & 1.21 \\
\hline \multicolumn{6}{|l|}{ Education of head } \\
\hline no h.s. degree & 0.91 & 0.95 & 0.81 & 0.86 & 0.88 \\
\hline h.s. degree & 0.95 & 1.00 & 0.93 & 0.91 & 0.95 \\
\hline some college & 0.93 & 1.00 & 0.88 & 0.90 & 0.93 \\
\hline college degree & 1.16 & 1.26 & 1.06 & 1.08 & 1.14 \\
\hline more than college degree & 1.05 & 1.22 & 1.47 & 1.53 & 1.32 \\
\hline
\end{tabular}

Sources: 1983-2004 Surveys of Consumer Finances and 1984-2005 Panel Studies of Income Dynamics, and authors' estimates.

Notes: When survey years do not line up between the SCF and PSID the wealth and income ratios are calculated as the SCF value for one year divided by the PSID values for the surrounding years. If surrounding years of the PSID are not available (e.g. for the 1983 SCF) the closest available PSID data is used for comparison. 
Table A3. Distribution of Saving Rates by Category, PSID and HRS

\begin{tabular}{|c|c|c|c|c|c|c|c|c|}
\hline $\begin{array}{c}\text { Multiple } \\
\text { of Income }\end{array}$ & $\begin{array}{c}\text { Total } \\
\text { saving }\end{array}$ & $\begin{array}{l}\text { Qquity- } \\
\text { type } \\
\text { Saving }\end{array}$ & $\begin{array}{c}\text { Housing } \\
\text { Saving }\end{array}$ & $\begin{array}{l}\text { Fixed- } \\
\text { price } \\
\text { Saving } \\
\end{array}$ & $\begin{array}{c}\text { Total } \\
\text { saving }\end{array}$ & $\begin{array}{c}\text { Equity- } \\
\text { type } \\
\text { Saving }\end{array}$ & $\begin{array}{c}\text { Housing } \\
\text { Saving }\end{array}$ & $\begin{array}{l}\text { Fixed- } \\
\text { price } \\
\text { Saving } \\
\end{array}$ \\
\hline & \multicolumn{4}{|c|}{ PSID: $1984-2005$ (6 subperiods) } & \multicolumn{4}{|c|}{ HRS: 1992-2004 (6 subperiods) } \\
\hline lt -10 & 0.1 & 0.0 & 0.0 & 0.0 & 0.4 & 0.1 & 0.1 & 0.3 \\
\hline-10 to -5 & 0.1 & 0.0 & 0.0 & 0.1 & 1.0 & 0.1 & 0.4 & 0.7 \\
\hline-5 to -1 & 3.1 & 0.3 & 0.9 & 2.3 & 9.3 & 0.9 & 3.4 & 6.9 \\
\hline-1 to -.5 & 3.5 & 0.4 & 1.4 & 2.8 & 6.9 & 1.0 & 3.2 & 5.9 \\
\hline-0.5 to -0.25 & 5.3 & 0.7 & 2.0 & 4.7 & 6.6 & 1.1 & 3.2 & 7.1 \\
\hline$-0.25-0$ & 19.6 & 3.4 & 9.1 & 23.5 & 13.5 & 2.5 & 6.7 & 19.4 \\
\hline 0 & 18.3 & 80.1 & 51.9 & 29.0 & 9.6 & 79.5 & 43.6 & 14.8 \\
\hline 0 to 0.25 & 32.2 & 11.9 & 28.6 & 26.8 & 18.5 & 8.6 & 23.6 & 21.4 \\
\hline 0.25 to 0.5 & 8.2 & 1.6 & 3.4 & 5.0 & 10.1 & 2.2 & 7.1 & 7.6 \\
\hline 0.5 to 1 & 5.3 & 0.9 & 1.7 & 3.1 & 9.6 & 1.8 & 4.6 & 6.6 \\
\hline 1 to 5 & 4.0 & 0.6 & 1.0 & 2.5 & 12.6 & 1.9 & 3.9 & 8.1 \\
\hline 5 to 10 & 0.2 & 0.0 & 0.0 & 0.1 & 1.4 & 0.1 & 0.3 & 0.9 \\
\hline$>10$ & 0.2 & 0.0 & 0.0 & 0.1 & 0.4 & 0.0 & 0.1 & 0.3 \\
\hline $\begin{array}{c}\text { sum } \\
\text { absolute }\end{array}$ & 100.1 & 100.0 & 100.0 & 100.0 & 100.0 & 100.0 & 100.0 & 100.0 \\
\hline \multirow[t]{2}{*}{ values $>1$} & 7.7 & 1.0 & 2.0 & 5.1 & 25.0 & 3.2 & 8.1 & 17.2 \\
\hline & \multicolumn{4}{|c|}{ PSID: 1984-1999 (3 subperiods) } & \multicolumn{4}{|c|}{ HRS: 1992-1998 (3 subperiods) } \\
\hline lt -10 & 0.0 & 0.0 & 0.0 & 0.0 & 0.4 & 0.1 & 0.1 & 0.3 \\
\hline-10 to -5 & 0.0 & 0.0 & 0.0 & 0.0 & 0.9 & 0.0 & 0.3 & 0.7 \\
\hline-5 to -1 & 1.8 & 0.3 & 0.7 & 1.2 & 8.9 & 0.8 & 3.1 & 6.6 \\
\hline-1 to -.5 & 2.6 & 0.4 & 1.1 & 1.7 & 6.6 & 0.9 & 3.2 & 5.9 \\
\hline-0.5 to -0.25 & 4.3 & 0.8 & 1.7 & 3.6 & 6.6 & 0.8 & 3.3 & 7.2 \\
\hline$-0.25-0$ & 18.9 & 4.0 & 9.2 & 22.1 & 13.9 & 2.2 & 7.0 & 19.6 \\
\hline 0 & 20.6 & 76.4 & 50.9 & 35.3 & 9.8 & 77.8 & 42.5 & 15.1 \\
\hline 0 to 0.25 & 37.2 & 15.0 & 31.5 & 28.5 & 19.3 & 10.0 & 24.9 & 22.5 \\
\hline 0.25 to 0.5 & 7.7 & 1.8 & 2.8 & 4.2 & 10.2 & 2.8 & 7.1 & 7.6 \\
\hline 0.5 to 1 & 4.3 & 1.0 & 1.3 & 2.2 & 9.6 & 2.2 & 4.6 & 6.3 \\
\hline 1 to 5 & 2.3 & 0.4 & 0.7 & 1.1 & 12.2 & 2.3 & 3.7 & 7.0 \\
\hline 5 to 10 & 0.1 & 0.0 & 0.0 & 0.0 & 1.2 & 0.1 & 0.2 & 0.8 \\
\hline$>10$ & 0.2 & 0.0 & 0.0 & 0.0 & 0.4 & 0.0 & 0.1 & 0.3 \\
\hline $\begin{array}{c}\text { sum } \\
\text { absolute }\end{array}$ & 100.1 & 100.0 & 100.0 & 100.0 & 100.0 & 100.0 & 100.0 & 100.0 \\
\hline \multirow[t]{2}{*}{ values $>1$} & 4.4 & 0.7 & 1.4 & 2.4 & 24.0 & 3.3 & 7.4 & 15.8 \\
\hline & \multicolumn{4}{|c|}{ PSID: 1999-2005 (3 subperiods) } & \multicolumn{4}{|c|}{ HRS: 1998-2004 (3 subperiods) } \\
\hline lt -10 & 0.1 & 0.0 & 0.0 & 0.1 & 0.5 & 0.1 & 0.1 & 0.3 \\
\hline-10 to -5 & 0.3 & 0.0 & 0.1 & 0.2 & 1.1 & 0.1 & 0.5 & 0.7 \\
\hline-5 to -1 & 4.4 & 0.4 & 1.1 & 3.5 & 9.7 & 1.1 & 3.8 & 7.3 \\
\hline-1 to -.5 & 4.4 & 0.4 & 1.6 & 3.8 & 7.2 & 1.1 & 3.1 & 5.9 \\
\hline-0.5 to -0.25 & 6.3 & 0.6 & 2.3 & 5.9 & 6.6 & 1.4 & 3.1 & 7.0 \\
\hline$-0.25-0$ & 20.3 & 2.9 & 8.9 & 24.9 & 13.2 & 2.8 & 6.3 & 19.2 \\
\hline 0 & 16.0 & 83.7 & 52.9 & 22.6 & 9.5 & 81.3 & 44.8 & 14.5 \\
\hline 0 to 0.25 & 27.2 & 8.8 & 25.6 & 25.1 & 17.8 & 7.3 & 22.3 & 20.3 \\
\hline 0.25 to 0.5 & 8.6 & 1.4 & 4.0 & 5.8 & 10.0 & 1.7 & 7.0 & 7.6 \\
\hline 0.5 to 1 & 6.3 & 0.8 & 2.1 & 4.0 & 9.6 & 1.5 & 4.7 & 6.9 \\
\hline 1 to 5 & 5.7 & 0.7 & 1.3 & 3.8 & 12.9 & 1.6 & 4.0 & 9.2 \\
\hline 5 to 10 & 0.3 & 0.1 & 0.1 & 0.2 & 1.6 & 0.1 & 0.3 & 1.0 \\
\hline$>10$ & 0.2 & 0.0 & 0.0 & 0.1 & 0.4 & 0.1 & 0.1 & 0.2 \\
\hline $\begin{array}{c}\text { sum } \\
\text { absolute }\end{array}$ & 100.0 & 100.0 & 100.0 & 100.0 & 100.0 & 100.0 & 100.0 & 100.0 \\
\hline values >1 & 10.9 & 1.3 & 2.6 & 7.9 & 26.1 & 3.0 & 8.8 & 18.7 \\
\hline
\end{tabular}




\section{RECENT WORKING PAPERS FROM THE}

\section{CENTER FOR RETIREMENT RESEARCH AT BOSTON COLLEGE}

Portfolio Choice in Retirement: Health Risk and the Demand for Annuities, Housing, and Risky Assets

Motohiro Yogo, January 2009

The Disappearing Defined Benefit Pension and its Potential Impact on the Retirement Incomes of Boomers

Barbara A. Butrica, Howard M. Iams, Karen E. Smith, and Eric J. Toder, January 2009

Retirement and Social Security: A Time Series Approach

Brendan Cushing-Daniels and C. Eugene Steuerle, January 2009

Economic Restructuring and Retirement in Urban China

John Giles, January 2009

Sources of Support for Pension Reform: A Cross-National Perspective Michelle Dion and Andrew Roberts, January 2009

The Long-Term Effect of the Divorce Revolution: Health, Wealth, and Labor Supply

Kristin Mammen, December 2008

The Response of Household Saving to the Large Shock of German Reunification Nicola Fuchs-Schündeln, November 2008

A Parsimonious Choquet Model of Subjective Life Expectancy

Alexander Ludwig and Alexander Zimper, November 2008

Risky Pensions and Household Saving Over the Life Cycle

David A. Love and Paul A. Smith, November 2008

Identifying Local Differences in Retirement Patterns

Leora Friedberg, Michael Owyang, and Anthony Webb, November 2008

What Effect Do Time Constraints Have on the Age of Retirement?

Leora Friedberg, Wei Sun, Anthony Webb, November 2008

Dual-Eligible Medicaid Spending: Are We on the Flat of the Curve?

Melissa A. Boyle, Joanna N. Lahey, and Margaret E. Czervionke, November 2008

All working papers are available on the Center for Retirement Research website (http://www.bc.edu/crr) and can be requested by e-mail (crr@bc.edu) or phone (617-552-1762). 